\title{
Prognostic and Genomic Analysis of Proteasome 20S Subunit Alpha (PSMA) Family Members in Breast Cancer
}

\author{
Chung-Chieh Chiao ${ }^{1,2,+}$, Yen-Hsi Liu ${ }^{2,+}$, Nam Nhut Phan ${ }^{3}$, Nu Thuy An Ton ${ }^{3}$, Hoang Dang Khoa Ta ${ }^{1,2} \oplus$, \\ Gangga Anuraga 1,2,4® , Do Thi Minh Xuan ${ }^{2}$, Fenny Fitriani ${ }^{4}{ }^{\circledR}$, Elvira Mustikawati Putri Hermanto ${ }^{4}$, \\ Muhammad Athoillah ${ }^{4} \oplus$, Vivin Andriani ${ }^{5}$, Purity Sabila Ajiningrum ${ }^{5}$, Yung-Fu Wu ${ }^{6}$, Kuen-Haur Lee ${ }^{1,2,7,8} \mathbb{D}^{\circ}$,

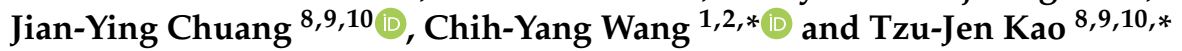

check for updates

Citation: Chiao, C.-C.; Liu, Y.-H.; Phan, N.N.; An Ton, N.T.; Ta, H.D.K.; Anuraga, G.; Minh Xuan, D.T.; Fitriani, F.; Putri Hermanto, E.M.; Athoillah, M.; et al. Prognostic and Genomic Analysis of Proteasome 20S Subunit Alpha (PSMA) Family Members in Breast Cancer. Diagnostics 2021, 11, 2220. https:// doi.org/10.3390/diagnostics11122220

Academic Editor: Charlotte K. Y. Ng

Received: 18 October 2021

Accepted: 22 November 2021

Published: 27 November 2021

Publisher's Note: MDPI stays neutral with regard to jurisdictional claims in published maps and institutional affiliations.

Copyright: (c) 2021 by the authors. Licensee MDPI, Basel, Switzerland. This article is an open access article distributed under the terms and conditions of the Creative Commons Attribution (CC BY) license (https:/ / creativecommons.org/licenses/by/ $4.0 /)$.
1 Ph.D. Program for Cancer Molecular Biology and Drug Discovery, College of Medical Science, Taipei Medical University, Taipei 11031, Taiwan; D621110004@tmu.edu.tw (C.-C.C.); d621109004@tmu.edu.tw (H.D.K.T.); g.anuraga@unipasby.ac.id (G.A.); khlee@tmu.edu.tw (K.-H.L.)

2 Graduate Institute of Cancer Biology and Drug Discovery, College of Medical Science and Technology, Taipei Medical University, Taipei 11031, Taiwan; M120110028@tmu.edu.tw (Y.-H.L.); m654110001@tmu.edu.tw (D.T.M.X.)

3 NTT Institute of Hi-Technology, Nguyen Tat Thanh University, Ho Chi Minh City 700000, Vietnam; pnnam@ntt.edu.vn (N.N.P.); tntan@ntt.edu.vn (N.T.A.T.)

4 Department of Statistics, Faculty of Science and Technology, Universitas PGRI Adi Buana, Surabaya 60234, Indonesia; fenny_f@unipasby.ac.id (F.F.); elvira@unipasby.ac.id (E.M.P.H.); athoillah@unipasby.ac.id (M.A.)

5 Department of Biological Science, Faculty of Science and Technology, Universitas PGRI Adi Buana, Surabaya 60234, Indonesia; v.andriani@unipasby.ac.id (V.A.); puritysabila@unipasby.ac.id (P.S.A.)

6 Department of Medical Research, Tri-Service General Hospital, School of Medicine, National Defense Medical Center, Taipei 11490, Taiwan; qrince@yahoo.com.tw

7 Cancer Center, Wan Fang Hospital, Taipei Medical University, Taipei 11031, Taiwan

8 TMU Research Center of Cancer Translational Medicine, Taipei Medical University, Taipei 11031, Taiwan; chuangcy@tmu.edu.tw

9 Ph.D. Program for Neural Regenerative Medicine, Taipei Medical University, Taipei 11031, Taiwan

10 Research Center of Neuroscience, Taipei Medical University, Taipei 11031, Taiwan

* Correspondence: chihyang@tmu.edu.tw (C.-Y.W.); geokao@tmu.edu.tw (T.-J.K.)

+ Equal contributor.

Abstract: The complexity of breast cancer includes many interacting biological processes, and proteasome alpha (PSMA) subunits are reported to be involved in many cancerous diseases, although the transcriptomic expression of this gene family in breast cancer still needs to be more thoroughly investigated. Consequently, we used a holistic bioinformatics approach to study the PSMA genes involved in breast cancer by integrating several well-established high-throughput databases and tools, such as cBioPortal, Oncomine, and the Kaplan-Meier plotter. Additionally, correlations of breast cancer patient survival and PSMA messenger RNA expressions were also studied. The results demonstrated that breast cancer tissues had higher expression levels of PSMA genes compared to normal breast tissues. Furthermore, PSMA2, PSMA3, PSMA4, PSMA6, and PSMA7 showed high expression levels, which were correlated with poor survival of breast cancer patients. In contrast, PSMA5 and PSMA8 had high expression levels, which were associated with good prognoses. We also found that PSMA family genes were positively correlated with the cell cycle, ubiquinone metabolism, oxidative stress, and immune response signaling, including antigen presentation by major histocompatibility class, interferon-gamma, and the cluster of differentiation signaling. Collectively, these findings suggest that PSMA genes have the potential to serve as novel biomarkers and therapeutic targets for breast cancer. Nevertheless, the bioinformatic results from the present study would be strengthened with experimental validation in the future by prospective studies on the underlying biological mechanisms of PSMA genes and breast cancer.

Keywords: PSMA family genes; bioinformatics; breast cancer 


\section{Introduction}

According to the most up-to-date statistics provided by the World Health Organization (WHO), the progressively increasing estimates of cancer cases and deaths in recent years make it one of the leading causes of premature deaths worldwide [1]. Although the cancer incidences and mortality rates vary significantly among ages, genders, and regions, it is indisputable that the cancer burden rises with age and population increment, particularly in China, North America, and Europe. Although lung cancer by far remains the leading killer of both sexes, it was recently displaced by breast cancer (BRCA) in terms of the most frequently diagnosed cases among women. Early detection and appropriate treatment are believed to play crucial roles in reducing the immense health and economic burdens imposed and extending the life expectancy for cancer survivors in general and particularly in terms of BRCA due to its invasiveness and aggressiveness. Compared to early and locally advanced BRCA, which is considered curable, advanced stages and metastatic $\mathrm{BRCA}$, along with inflammatory BRCA (IBC) and triple-negative BRCA (TNBC), lack druggable molecular targets, thus resulting in limited treatment regimens [2-4]. Therefore, unremitting efforts have been made to enhance the precision of the prognostic predictions of female BRCA; among these, molecular signatures and targeted therapies have emerged as promising treatment regimens of distinct subtypes [5].

While existing evidence-based treatment strategies use the classical hormonal factors, including the progesterone receptor (PR), estrogen receptor (ER), and human epidermal growth factor receptor (HER)-2, to stratify BRCA prior to determining the most suitable treatment for patients, plenty of immunohistochemical markers, such as Ki-67, p53, and E-cadherin, are simultaneously employed as predictive tools for those subtypes that still lack druggable molecular targets [6-10]. Over the past few years, studies of the genetic alterations and dysfunction of signal transduction pathways that highly contribute to the advent of numerous predictive biomarkers, including transcriptomic data and messenger (m)RNA levels, have opened up the possibility of having effective therapeutics and have been useful in predicting tumor grades, drug responsiveness, and risks of recurrence of intrinsic subtypes [11-13].

The degradation of obsolete or damaged endogenous proteins is catalyzed by the $26 \mathrm{~S}$ proteasome, which is comprised of two complexes, namely 19S (the regulatory complex) and $20 \mathrm{~S}$ (the core complex) [14,15]. There is a growing body of studies regarding the involvement of proteases in various critical cellular processes of cancer cells, such as proliferation, apoptosis, the cell cycle, DNA repair, invasion, and metastasis [16-18]. Within the $20 \mathrm{~S}$ core complex, proteasome alpha (PSMA) subunits are the main subunits, which are constituted of eight unique alpha subunits (PSMA1 8). Associations of these PSMA genes with cancers have been documented [19]. For instance, significant increases in PSMA1 and PSMA5 were found in pulmonary neuroendocrine tumors relative to normal tissues [20]. The previous literature also demonstrated implications of proteasome subunit genes in several cancerous diseases, namely BRCA, lung cancer, hepatocellular carcinoma (HCC), and colorectal cancer (CRC). Of the proteasome genes, PSMB5 and PSMD10 were reported to be associated with the proliferation of TNBC and to promote the invasiveness and metastasis of HCC [21-23].

To study the roles of PSMA family genes in BRCA, it is worth comprehensively screening their interactions in an integrated model using a holistic approach. To implement this high-throughput analysis, we combined multiple tools and databases containing transcriptomic expressions of PSMA genes. Integrating multiple datasets from these databases can provide a high degree of evidence from various studies in different populations using either raw or processed data, such as the Gene Expression Omnibus (GEO) (https:/ / www.ncbi.nlm.nih.gov/geo/ accessed on 1 February 2021), a biomedical repository providing transcriptomic datasets for both microarray and next-generation sequencing platforms [24-32]. Changes in the mRNA expression levels of genes, sometimes an order of magnitude higher or lower in tumors than in normal matched tissues, illustrate, respectively, their roles as either oncogenes or tumor suppressors in cancer [33-35]. Applying 
this concept to BRCA and PSMA family genes, we used multiple datasets from public databases to study the expressions of PSMA genes in multiple subtypes of BRCA together with interaction networks to trace potential coexpressed targets with PSMA genes.

\section{Materials and Methods}

\subsection{UALCAN Analyses}

Transcriptomic expressions of PSMA members were analyzed in BRCA samples using the UALCAN (http:/ / ualcan.path.uab.edu/ accessed on 1 February 2021) platform. UALCAN collected the Cancer Genome Atlas (TCGA) level 3 RNA-Seq as well as the patients data from different cancer types. With genes of interest, UALCAN allows users to identify biomarkers to verify gene expressions with multiple clinical factors. We created a boxplot of PSMA mRNA expression levels measured in BRCA specimens (red) compared to their normal counterparts (blue) obtained from the UALCAN database, and used Student's $t$-test to calculate the significant differences between groups with a $p$-value threshold of $0.01[36]$.

\subsection{Kaplan-Meier (KM) Plot of Survival Analysis}

To explore transcriptomic effects of PSMA gene family members to relapse-free survival (RFS) of BRCA patients, a survival analysis using the KM plotter database (https://kmplot.com/ accessed on 1 February 2021) was conducted. The breast cancer patients $(n=4929)$ were collected from the Gene Expression Omnibus (GEO) and TCGA (HG-U133A 2.0, Affymetrix HG-U133A, and HG-U133 Plus 2.0 microarrays) as previously described $[37,38]$. The KM plotter was applied with default settings for the survival analysis, including log-rank $p$ values, with the Jet set as the best probe set, and hazard ratios (HRs) with $95 \%$ confidence intervals (CIs). Log-rank $p<0.05$ was considered statistically significant.

\subsection{Analysis of Protein Expressions in Human Clinical Specimens}

The Human Protein Atlas (HPA, www.proteinatlas.org accessed on 1 February 2021) provides a wealth of information on sequences, pathologies, expressions, and distributions in various cancer tissues. The first version of this database contained more than 400,000 high-resolution photo corresponding to more than 700 antibodies to human proteins [39-41]. This study analyzed the differential statuses of protein expressions and localization of select members of the PSMA family protein expression in breast tissues [42,43].

\subsection{Functional Enrichment Analysis of PSMA Family Members}

We extracted data from the METABRIC and TCGA datasets in the cBioPortal (https:/ / www.cbioportal.org accessed on 1 February 2021) database to analyze functional enrichment, and further used the MetaCore Analysis (https:// portal.genego.com accessed on 1 February 2021) to explore the downstream network, and $p<0.05$ was set as the boundary criterion as we previously described [44-48].

\subsection{DNA Methylation}

To assess the methylation status of a target gene, we utilized Methsurv (https:/ / biit.cs. ut.ee/methsurv / accessed on 1 February 2021) to produce a heatmap of the various DNA methylated areas [49]. To illustrate DNA methylation levels, beta values were employed (ranging from 0 to 1$)$. The beta value for each CpG site is calculated using $\mathrm{M} /(\mathrm{M}+\mathrm{U}+100)$. The methylated and unmethylated intensities are represented by $\mathrm{M}$ and $\mathrm{U}$, respectively.

\section{Results}

\subsection{PSMA Family Members Play Crucial Roles in BRCA Development}

The previous literature reported that several members of the PSMA gene family were involved in cancer onset and development. Therefore, studying all of these PSMA members in BRCA is an essential approach that would provide detailed evidence suggesting their 
potential roles as biomarkers for BRCA subtypes. The UALCAN analysis found that the PSMA1 7 genes had significantly higher transcriptomic expression levels in BRCA tissues than normal tissues, which was contradictory to the results for the PSMA8 gene (Figure 1). It was noted that, in further analyses of the expressions of PSMA family genes in BRCA patients, their expression levels were highly correlated with tumor grades, tumor stages, and metastatic events (Figure 2).

(A)

(A) Expression of PSMA L in BRCA based o n breast tancer

(B) Expression of P PSMA2 i i B BCC b based on breast taner

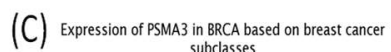

(D) Expression of PSMAA Ain BCCA based on breast tancer

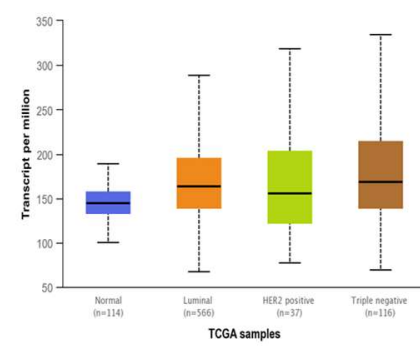

(E) Expression of PsMas in BRCA based on breast tancer

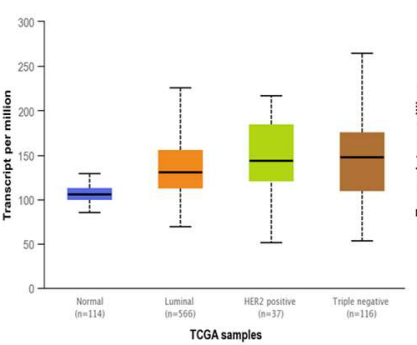

(F)

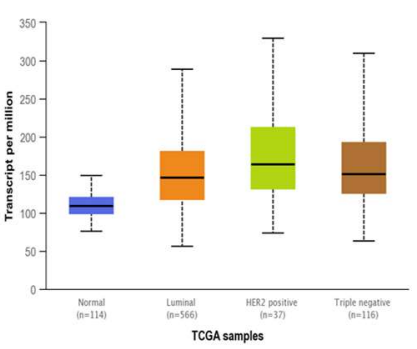

(G)

Expression of PSMA7 in BRCA based on breast cancer

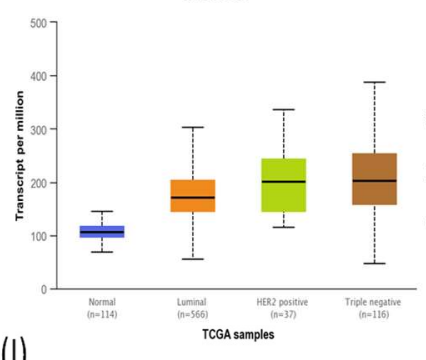

subclasses subclasses
in BRC bas

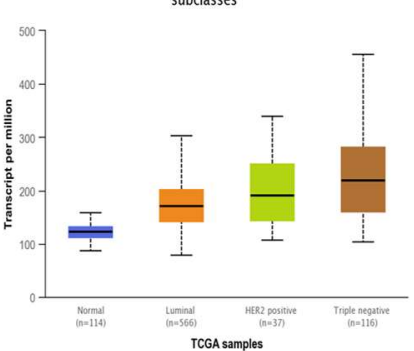

(H) H) Expression of PSMA8 in BRCA based on breast cancer (1)
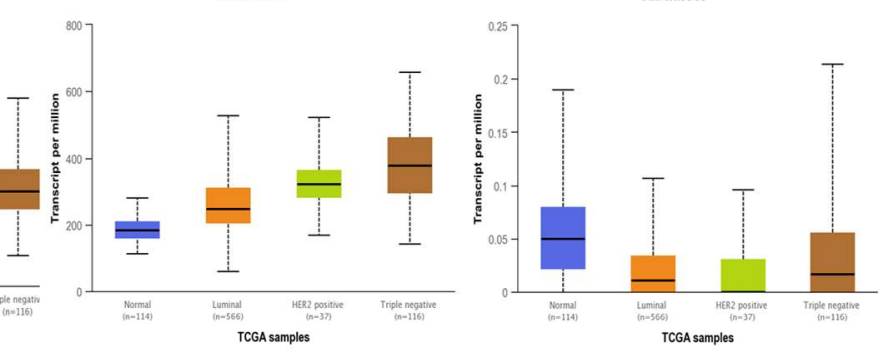

(I)

\begin{tabular}{|c|c|c|c|c|c|c|c|c|}
\hline Comparison and $\mathrm{P}$ value & PSMA1 & PSMA2 & PSMA3 & PSMA4 & PSMA5 & PSMA6 & PSMA7 & PSMA8 \\
\hline Normal-vs-Luminal & $1.62 \mathrm{E}-12$ & $<1 \mathrm{E}-12$ & $<1 \mathrm{E}-12$ & $1.62 \mathrm{E}-12$ & $<1 \mathrm{E}-12$ & $<1 \mathrm{E}-12$ & $<1 \mathrm{E}-12$ & $3.63 \mathrm{E}-02$ \\
\hline Normal-vs-HER2 Positive & $2.10 \mathrm{E}-02$ & $1.71 \mathrm{E}-06$ & $6.05 \mathrm{E}-07$ & $1.12 \mathrm{E}-06$ & 2.47E-10 & $1.03 \mathrm{E}-06$ & $3.14 \mathrm{E}-09$ & $5.54 \mathrm{E}-05$ \\
\hline Normal-vs-TNBC & $3.43 \mathrm{E}-08$ & $2.34 \mathrm{E}-12$ & 2.09E-12 & $1.62 \mathrm{E}-12$ & $<1 \mathrm{E}-12$ & $1.05 \mathrm{E}-07$ & $<1 \mathrm{E}-12$ & $1.74 \mathrm{E}-02$ \\
\hline Luminal-vs-HER2 Positive & 7.12E-01 & $7.11 E-02$ & $1.65 \mathrm{E}-01$ & $7.06 \mathrm{E}-02$ & $1.76 \mathrm{E}-02$ & 2.83E-01 & $3.05 \mathrm{E}-02$ & $1.05 \mathrm{E}-01$ \\
\hline Luminal-vs-TNBC & $1.67 \mathrm{E}-01$ & $3.21 \mathrm{E}-02$ & 2.96E-01 & $9.38 \mathrm{E}-07$ & $6.42 \mathrm{E}-04$ & 2.84E-01 & $6.57 \mathrm{E}-08$ & $8.42 \mathrm{E}-03$ \\
\hline HER2 Positive-vs-TNBC & $3.16 \mathrm{E}-01$ & $9.81 \mathrm{E}-01$ & $5.34 \mathrm{E}-01$ & $6.08 \mathrm{E}-01$ & $8.25 \mathrm{E}-01$ & $1.63 \mathrm{E}-01$ & $3.15 \mathrm{E}-01$ & $4.42 \mathrm{E}-03$ \\
\hline
\end{tabular}

Figure 1. Proteasome 20S subunit alpha (PSMA) gene family transcription levels in different stages of breast cancer (BRCA) patients (UALCAN analysis). (A-H) Box plot of PSMA gene family and primary tumor (BRCA) tissues. The box plot shows comparisons of the expressions of TCGA data from the PSMA gene family in different stages of breast cancer, including normal samples $(n=114)$, luminal $(n=566)$, HER2-positive $(n=37)$, and triple-negative tumors $(n=116)$. Statistical significance is represented by $p<0.05$. (I) The table shows relative expression levels of PSMA family genes in normal samples and different BRCA subtypes; $p<0.05$ was considered statistically significant. 


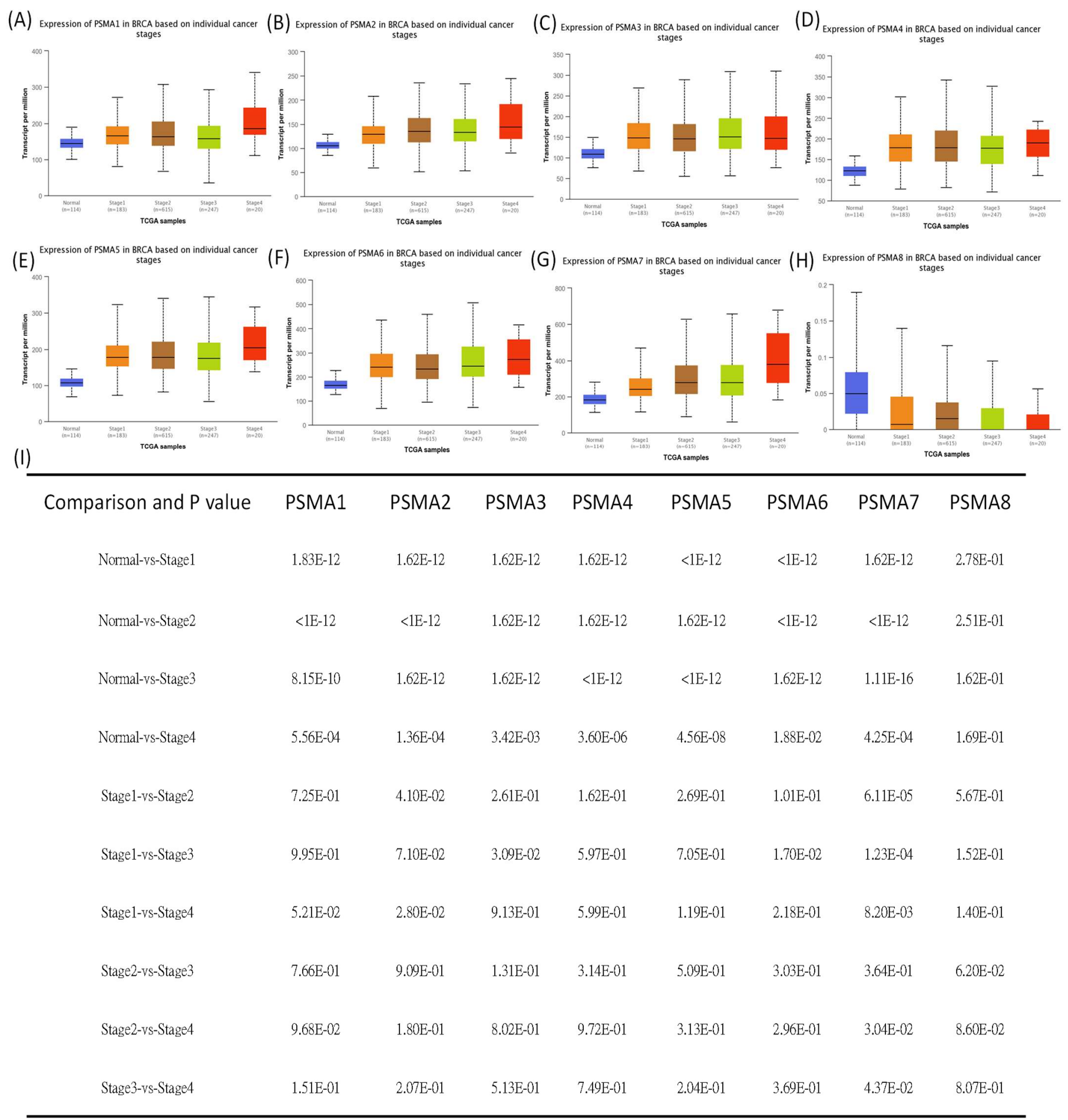

Figure 2. Proteasome 20S subunit alpha (PSMA) family gene transcription levels in different stages of breast cancer patients. (A-H) Box plot shows relative expression levels of PSMA family genes in normal samples $(n=114)$, and stage $1(n=183)$, stage $2(n=615)$, stage $3(n=247)$, and stage 4 breast cancer $(n=20)$. (I) The table shows relative expression levels of PSMA family genes in different BRCA stages; $p<0.05$ was considered statistically significant.

\subsection{Protein Expression Levels and Prognostic Values of PSMA Family Members in $B R C A$ Specimens}

Together with a transcriptomic expression analysis of PSMA genes, we further carried out an analysis at the proteomic level in clinical human BRCA specimens. This could potentially provide interesting correlations between PSMA genes and BRCA subtypes 
through antibody intensity levels. The protein expression levels of PSMA family members and their clinical relevance were determined by analyzing the Human Protein Atlas (HPA) database. PSMA3, PSMA6, and PSMA7 were found to have high protein expression levels, and most PSMA family members showed medium protein expression levels in BRCA specimens (Figure 3). The KM plot of this database also showed that PSMA1, PSMA2, PSMA3, PSMA4, PSMA6, and PSMA7 had high expression levels in BRCA tissues relative to normal breast cells and predicted poor survival, whereas PSMA5 and PSMA8 did not. These data implied that most PSMA family members might have oncogenic roles in BRCA progression (Figure 4A). We also investigated mRNA expression correlations among PSMA gene family members (Figure 4B) and co-regulated molecules (Figure 4C). Meanwhile, DNA methylation is an epigenetic modification that has been involved in the formation of several malignancies. We present a heatmap of DNA methylation grouping the expression levels of the PSMA gene family in breast cancer, as well as its predictive relevance. Among the PSMA family genes, we observed that cg07435350, cg26165081, cg26868250 of PSMA1; cg10778455, cg106226670, cg15202134 of PSMA2; cg08095532, cg14211735 of PSMA4; cg08250978, cg13170147 of PSMA5; cg01757308 of PSMA6; cg17665883 of PSMA7; cg11858305, cg15865827, cg00262344, cg06377543, cg03162994, cg22027766, cg259833544, cg01070760, cg21248196 of PSMA8 indicated the highest level of DNA methylation in breast cancer (Figure S1).

\subsection{Pathway and Network Analysis of PSMA Family Genes}

Enriched biological processes shown by GeneGo MetaCore version 21.1 (Cortellis, Philadelphia, PA, USA) software revealed that genes coexpressed with PSMA family genes had high correlations with cancer developmental processes. In addition, MetaCore can be used to construct biological networks specific for each tissue from gene lists. Lists of genes coexpressed with PSMA genes obtained from TCGA and METABRIC were input to the MetaCore platform. The results showed that these genes were associated with various signal pathways in cancer progression. The top $10 \%$ of coexpressed genes for each PSMA member were also used for enrichment analysis. We found that genes coexpressed with PSMA1 were involved in cell cycle-related pathways and networks, such as "Cell cycle_Role of SCF complex in cell cycle regulation", "Immune response_Antigen presentation by MHC class I, classical pathway", "Apoptosis and survival_Regulation of apoptosis by mitochondrial proteins", "Proteolysis_Putative ubiquitin pathway", and "Ubiquinone metabolism" (Figure 5, Supplementary Table S1). Genes coexpressed with PSMA2 were involved in metabolism-related pathways and networks, such as "Propionate metabolism p.2", "Leucine, isoleucine, and valine metabolism p.2", "Development_Positive regulation of WNT/Beta-catenin signaling in the cytoplasm", "Tricarbonic acid cycle", and "N-Glycan biosynthesis p.1" (Figure 6, Supplementary Table S2). Genes coexpressed with PSMA3 were involved in immune-related pathways and networks, such as "Immune response_Antigen presentation by MHC class I, classical pathway", "Cell cycle_Spindle assembly and chromosome separation ", "Immune response_Induction of the antigen presentation machinery by IFN-gamma ", "CFTR folding and maturation (normal and CF)", and "Immune response_Antigen presentation by MHC class I: cross-presentation" (Figure 7, Supplementary Table S3). Genes coexpressed with PSMA4 were involved in inflammation-related pathways and networks, such as "Immune response_IFN-alpha/beta signaling via JAK/STAT", "Immune response_Antigen presentation by MHC class I, classical pathway", "Release of proinflammatory mediators and elastolytic enzymes by alveolar macrophages in COPD", "Immune response_Induction of the antigen presentation machinery by IFN-gamma", and "COVID-19: immune dysregulation" (Figure 8, Supplementary Table S4) [50-53]. Genes coexpressed with PSMA5 were involved in cell cycle-related pathways and networks, such as "Cell cycle_The metaphase checkpoint", "Immune response_IFN-alpha/beta signaling via JAK/STAT", "Immune response_Antigen presentation by MHC class I, classical pathway", "Cell cycle_Role of APC in cell cycle regulation", and "Cell cycle_Spindle assembly and chromosome separation" (Figure 9, Supplementary Table S5). Genes coexpressed with 
PSMA6 were involved in cell cycle-related pathways and networks, such as "Immune response_Antigen presentation by MHC class I, classical pathway", "Apoptosis and survival_Regulation of apoptosis by mitochondrial proteins", "Immune response_Induction of the antigen presentation machinery by IFN-gamma", "Oxidative stress_Role of ASK1 under oxidative stress", and "Immune response_Antigen presentation by MHC class II" (Figure 10, Supplementary Table S6).

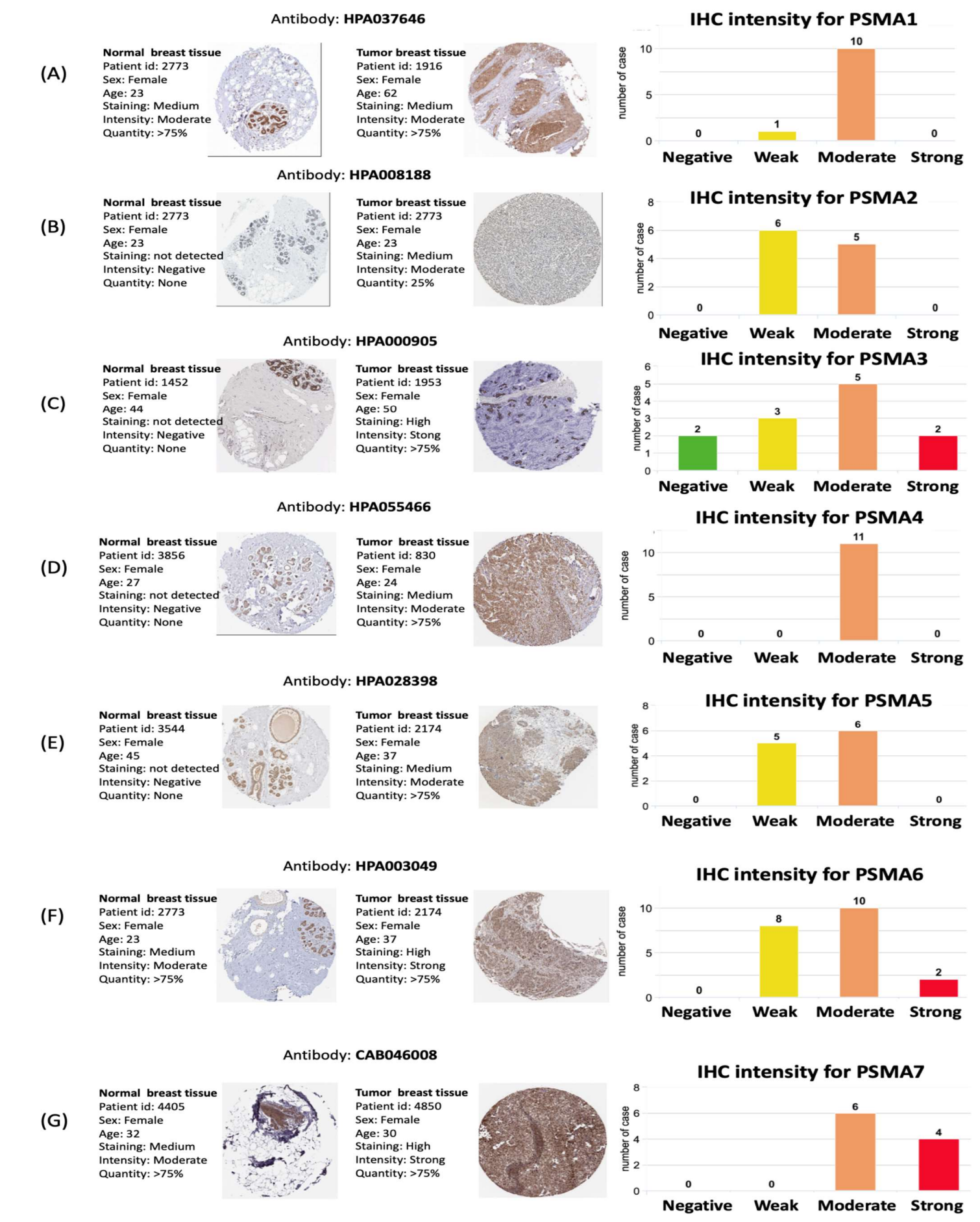

Figure 3. Protein expression levels of proteasome 20S subunit alpha (PSMA) family members across clinical breast cancer specimens from the Human Protein Atlas. (A-G) PSMA3, PSMA6, and PSMA7 showed high protein expression levels, and most PSMA family members showed medium protein expression levels in breast cancer specimens. All IHC images and patient information were acquired from the Human Protein Atlas. 
(A)
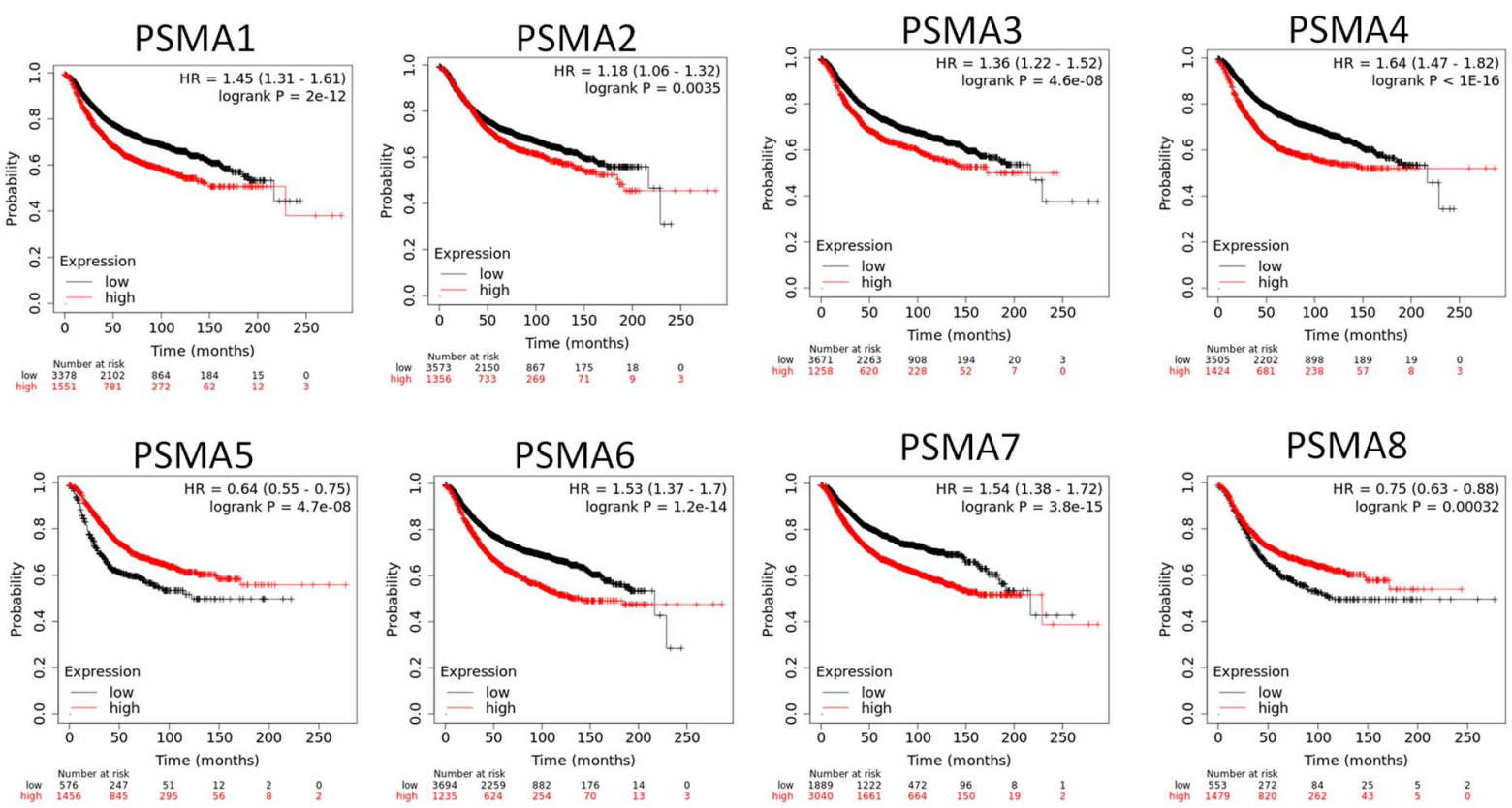

(B)

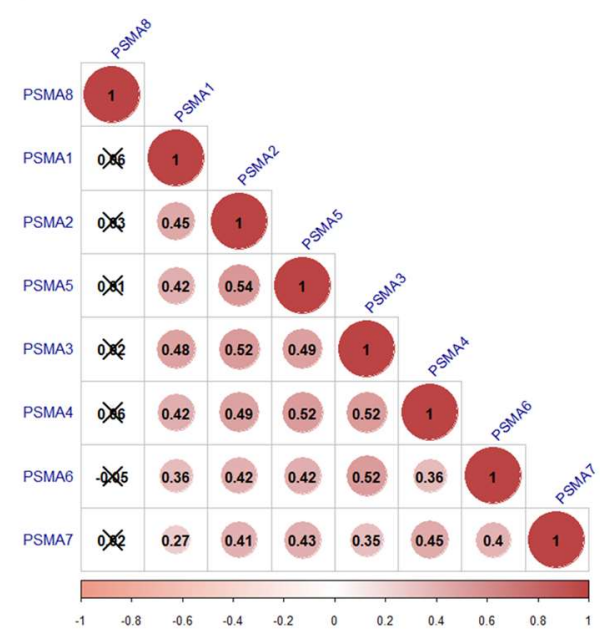

(C)

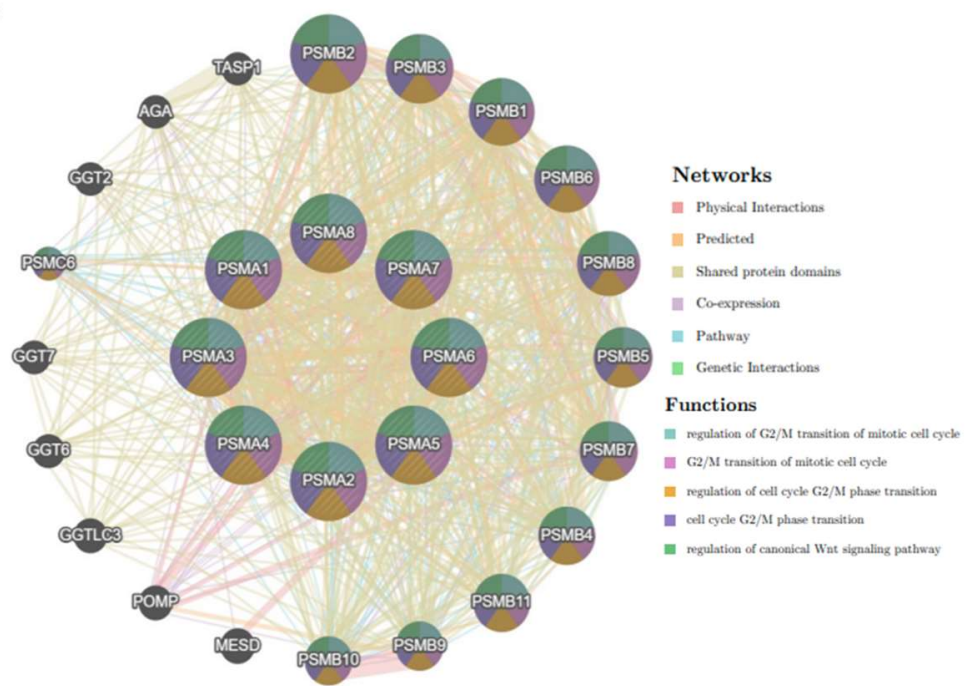

Figure 4. Prognosis and correlation analysis of proteasome 20S subunit alpha (PSMA) family genes in breast cancer patients. (A) A recurrence-free survival (RFS) dataset was used for the analysis. An auto-cutoff was applied in this analysis to differentiate patients into two groups based on the best cutoff value of PSMA mRNA. Higher and lower expression levels of PSMA mRNA than the cutoff value are, respectively, indicated in red and black. Significant correlations were shown between high expression levels of PSMA1, PSMA2, PSMA3, PSMA4, PSMA6, and PSMA7 with poor survival outcomes in breast cancer patients $(\mathrm{n}=4929)$. (B) Correlations between PSMA family genes in breast cancer patients, and insignificant correlations are marked by crosses. (C) Co-regulated molecules for PSMA family genes were analyzed with the GeneMania platform. 

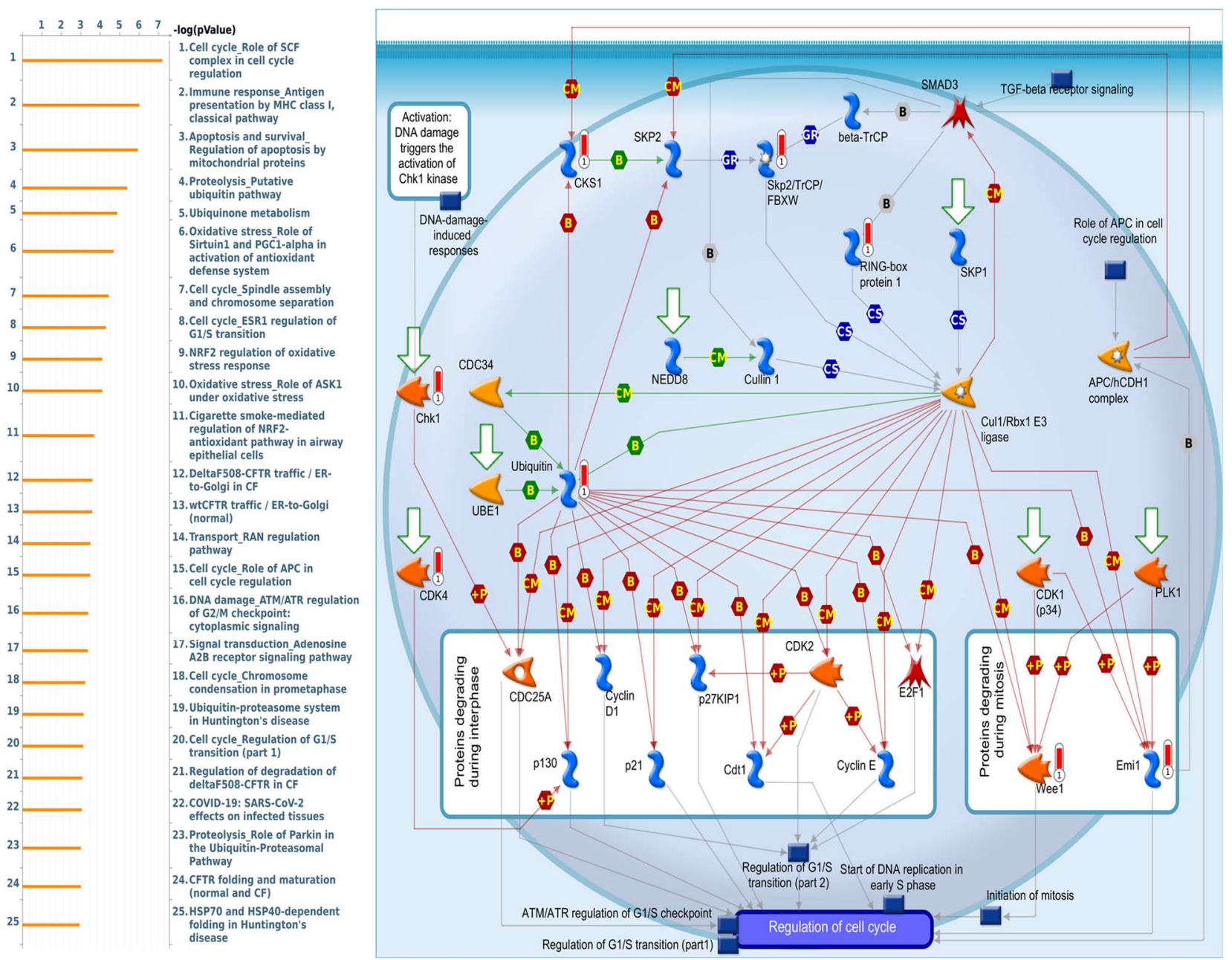

Figure 5. MetaCore pathway analysis of the coexpression gene network of proteasome 20S subunit alpha 1 (PSMA1) in breast cancer patients. We used the MetaCore platform to analyze genes coexpressed with PSMA1 from the associated METABRIC and TCGA datasets, and downstream pathway analyses revealed that "Cell cycle_Role of SCF complex in cell cycle regulation" participates in breast cancer development. 



Figure 6. MetaCore pathway analysis of the coexpression gene network of proteasome 20S subunit alpha 2 (PSMA2) in breast cancer patients. We used the MetaCore platform to analyze genes coexpressed with PSMA2 from the associated METABRIC and TCGA datasets, and downstream pathway analyses revealed that "Propionate metabolism p.2" participates in breast cancer development.
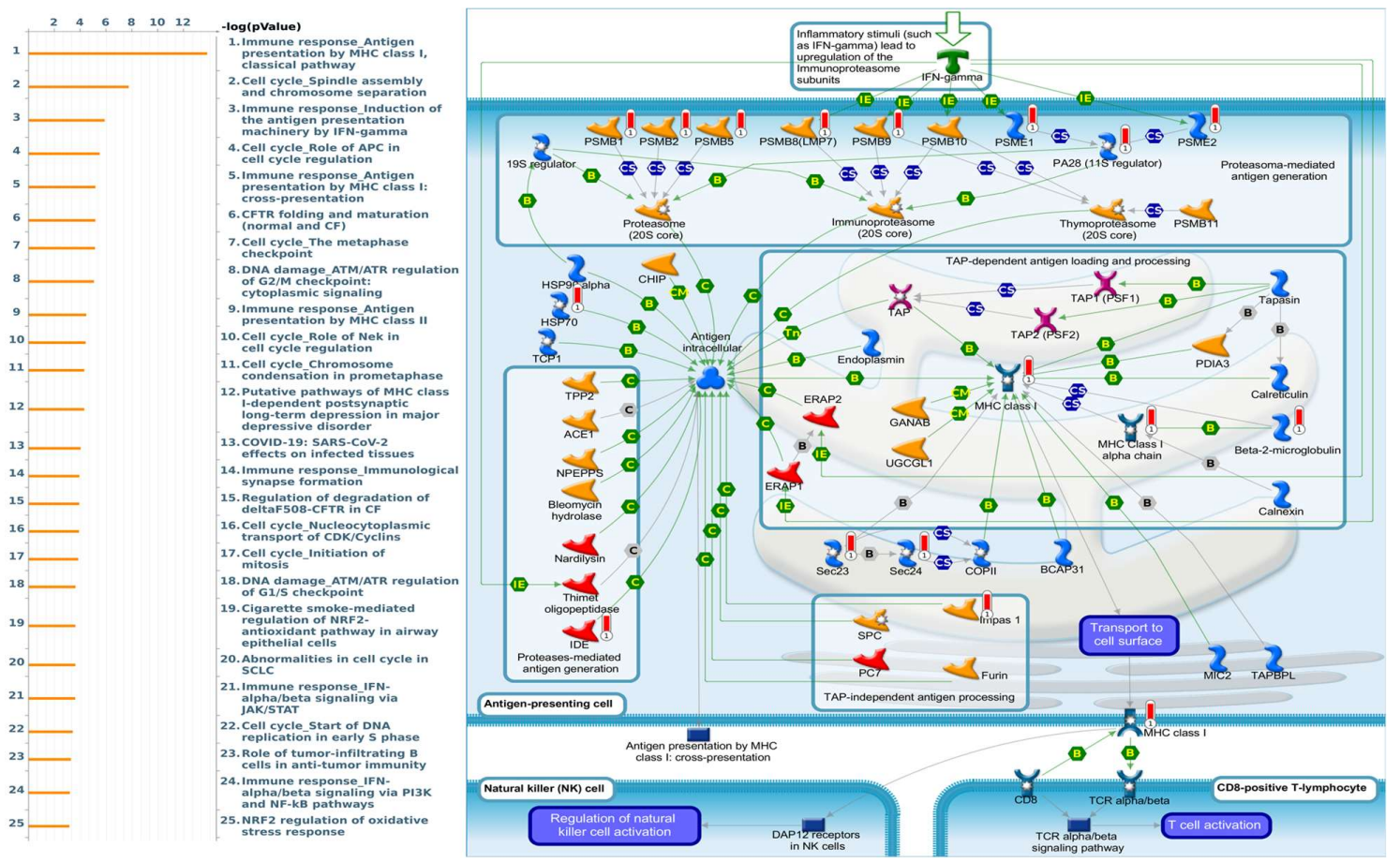

Figure 7. MetaCore pathway analysis of the coexpression gene network of proteasome 20S subunit alpha 3 (PSMA3) in breast cancer patients. We used the MetaCore platform to analyze genes coexpressed with PSMA3 from the associated METABRIC and TCGA datasets, and downstream pathway analyses revealed that "Immune response_Antigen presentation by MHC class I, classical pathway" participates in breast cancer development. 


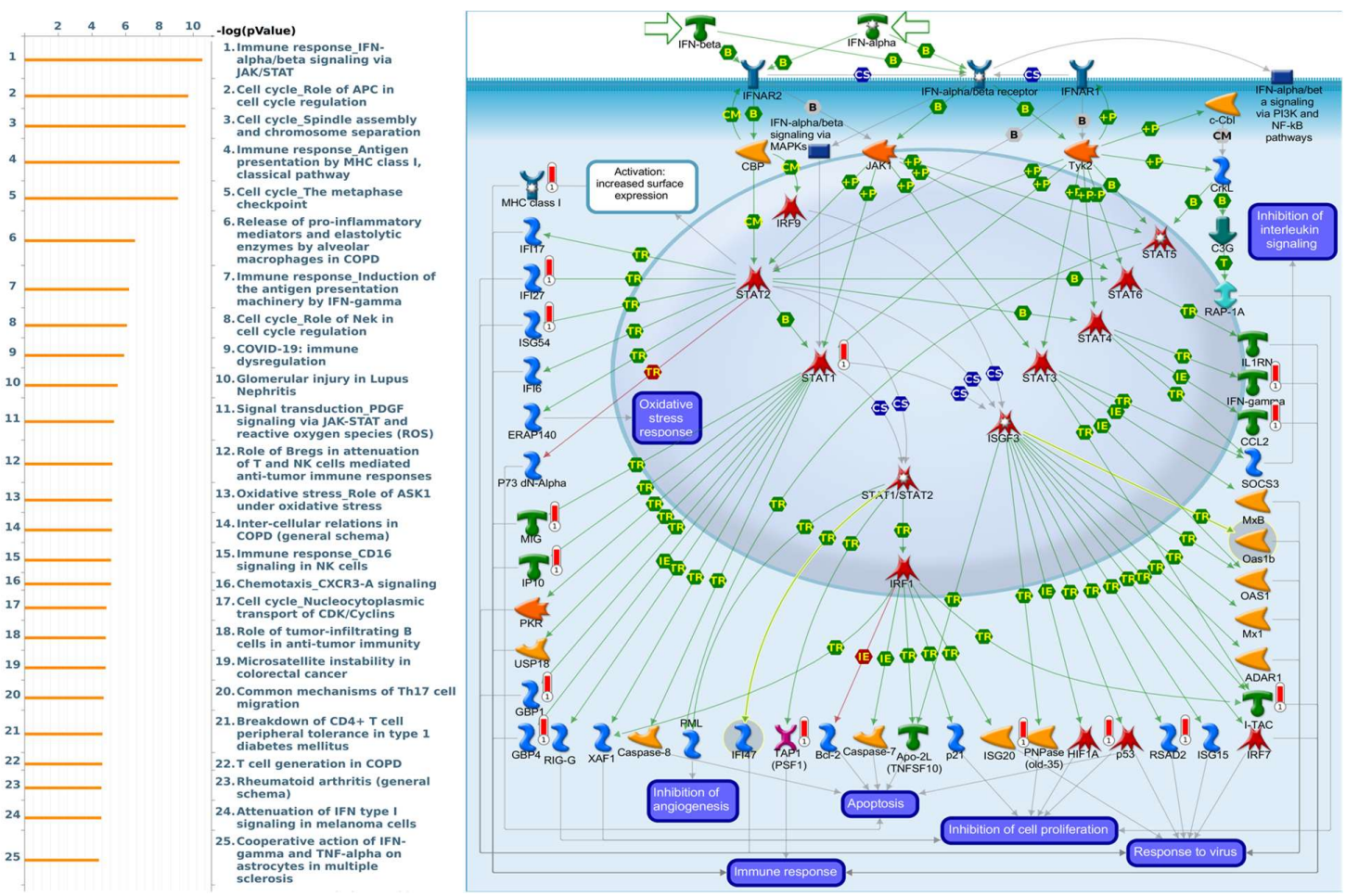

Figure 8. MetaCore pathway analysis of the coexpression gene network of proteasome 20S subunit alpha 4 (PSMA4) in breast cancer patients. We used the MetaCore platform to analyze genes coexpressed with PSMA4 from the associated METABRIC and TCGA datasets, and downstream pathway analyses revealed that "Immune response_IFN-alpha and beta signaling via JAK/STAT" participates in breast cancer development.

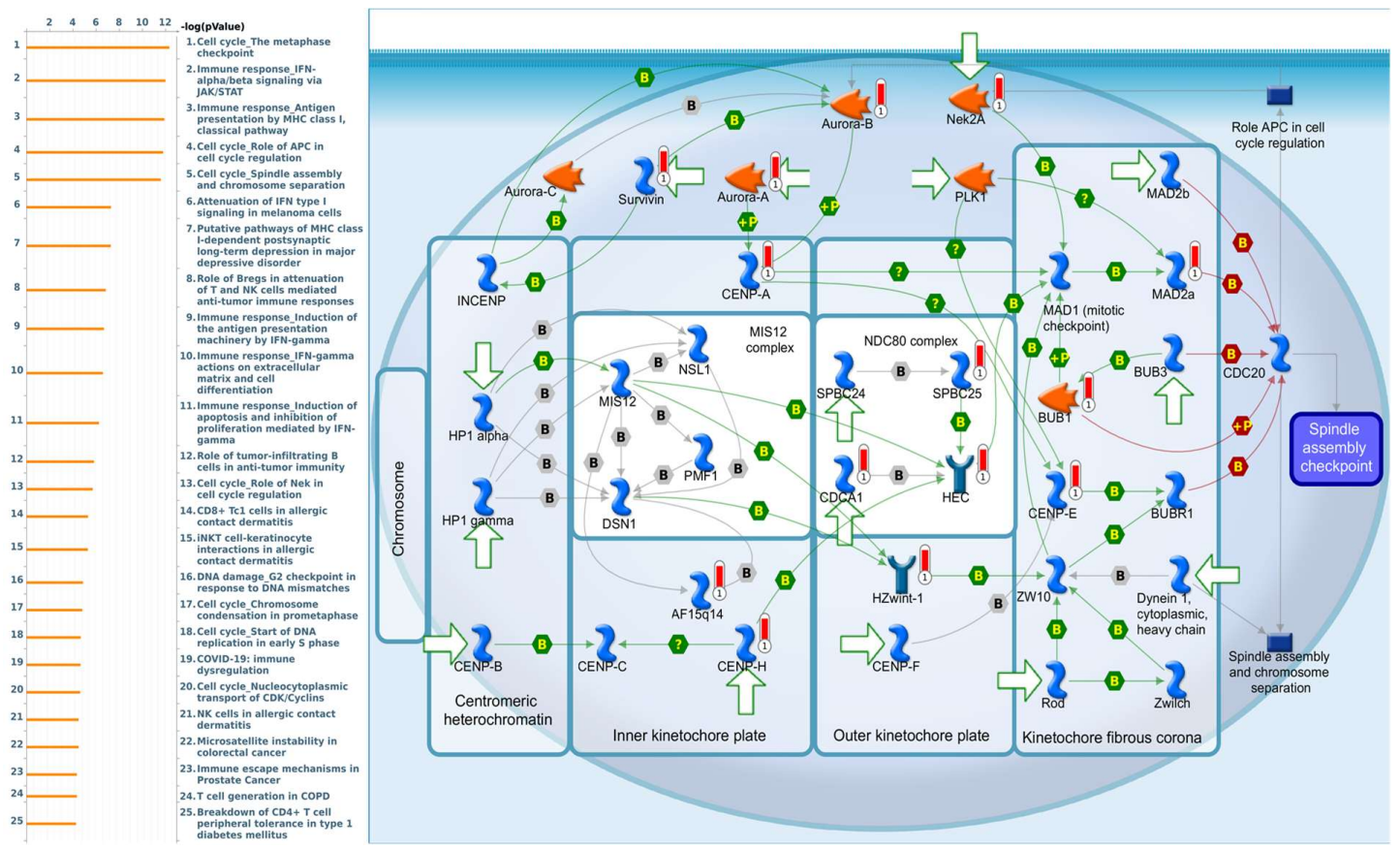

Figure 9. MetaCore pathway analysis of the coexpression gene network of proteasome 20S subunit alpha 5 (PSMA5) in breast cancer patients. We used the MetaCore platform to analyze genes coexpressed with PSMA5 from the associated METABRIC and TCGA datasets, and downstream pathway analyses revealed that "Cell cycle_The metaphase checkpoint" participates in breast cancer development. 

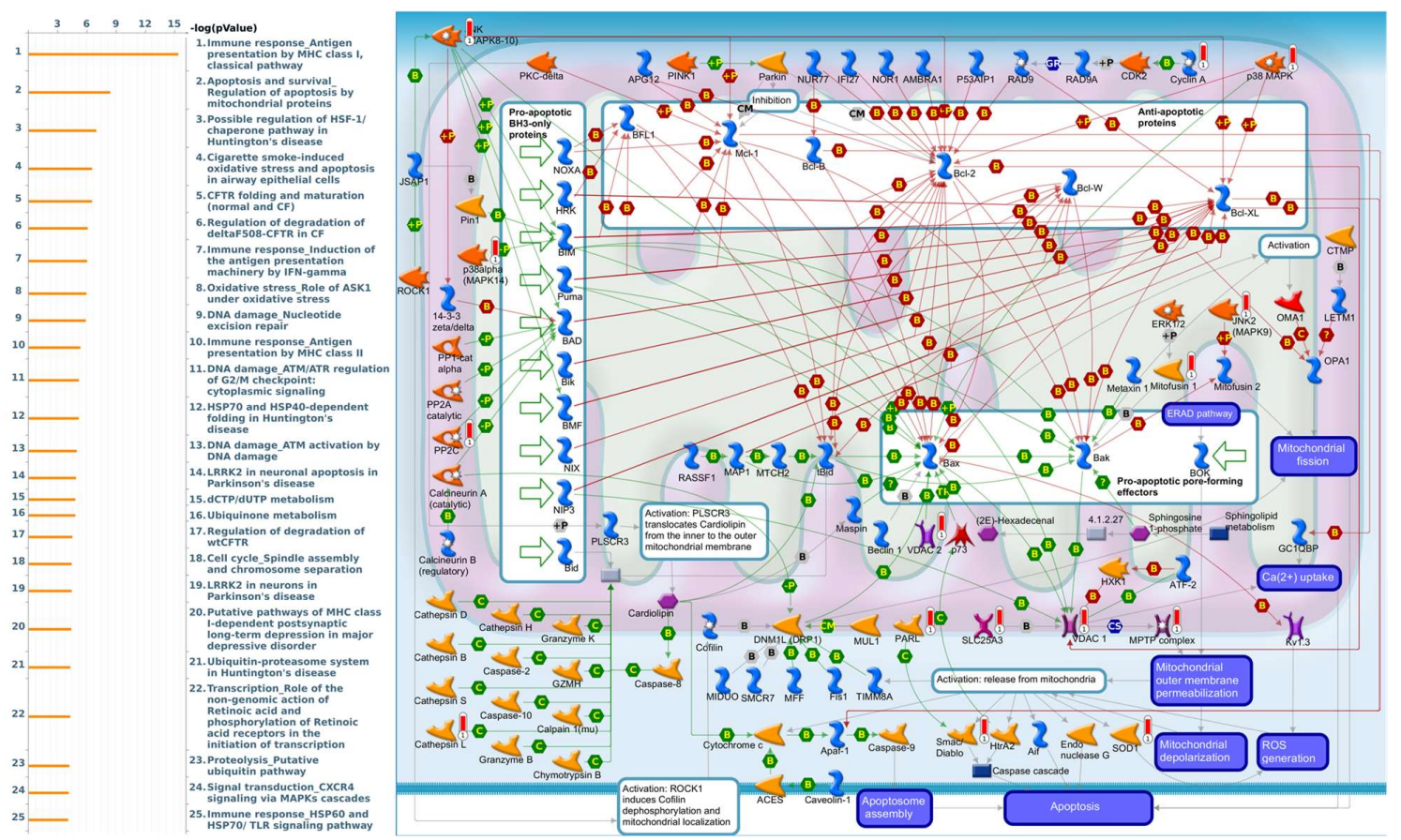

Figure 10. MetaCore pathway analysis of the coexpression gene network of proteasome 20S subunit alpha 6 (PSMA6) in breast cancer patients. We used the MetaCore platform to analyze genes coexpressed with PSMA6 from the associated METABRIC and TCGA datasets, and downstream pathway analyses revealed that "Apoptosis and survival_Regulation of apoptosis by mitochondrial proteins" participates in breast cancer development.

Genes coexpressed with PSMA7 were involved in cell cycle-related pathways and networks, such as "Cell cycle_Role of APC in cell cycle regulation", "Cell cycle_The metaphase checkpoint", "Cell cycle_Spindle assembly and chromosome separation", "DNA damage_ATM/ATR regulation of $\mathrm{G}_{2} / \mathrm{M}$ checkpoint: nuclear signaling", and "DNA damage_Intra S-phase checkpoint" (Figure 11, Supplementary Table S7). Genes coexpressed with PSMA8 were involved in cell immune-related pathways and networks, such as "Immune response_NF-AT in immune response", "Immune response_Inhibitory PD-1 signaling in T cells", "Breakdown of CD4+ T cell peripheral tolerance in type 1 diabetes mellitus", "Immunological synapse between dendritic and $\mathrm{CD} 8^{+} \mathrm{T}$ cells in allergic contact dermatitis", and "B cell signaling in hematological malignancies" (Figure 12, Supplementary Table S8). 


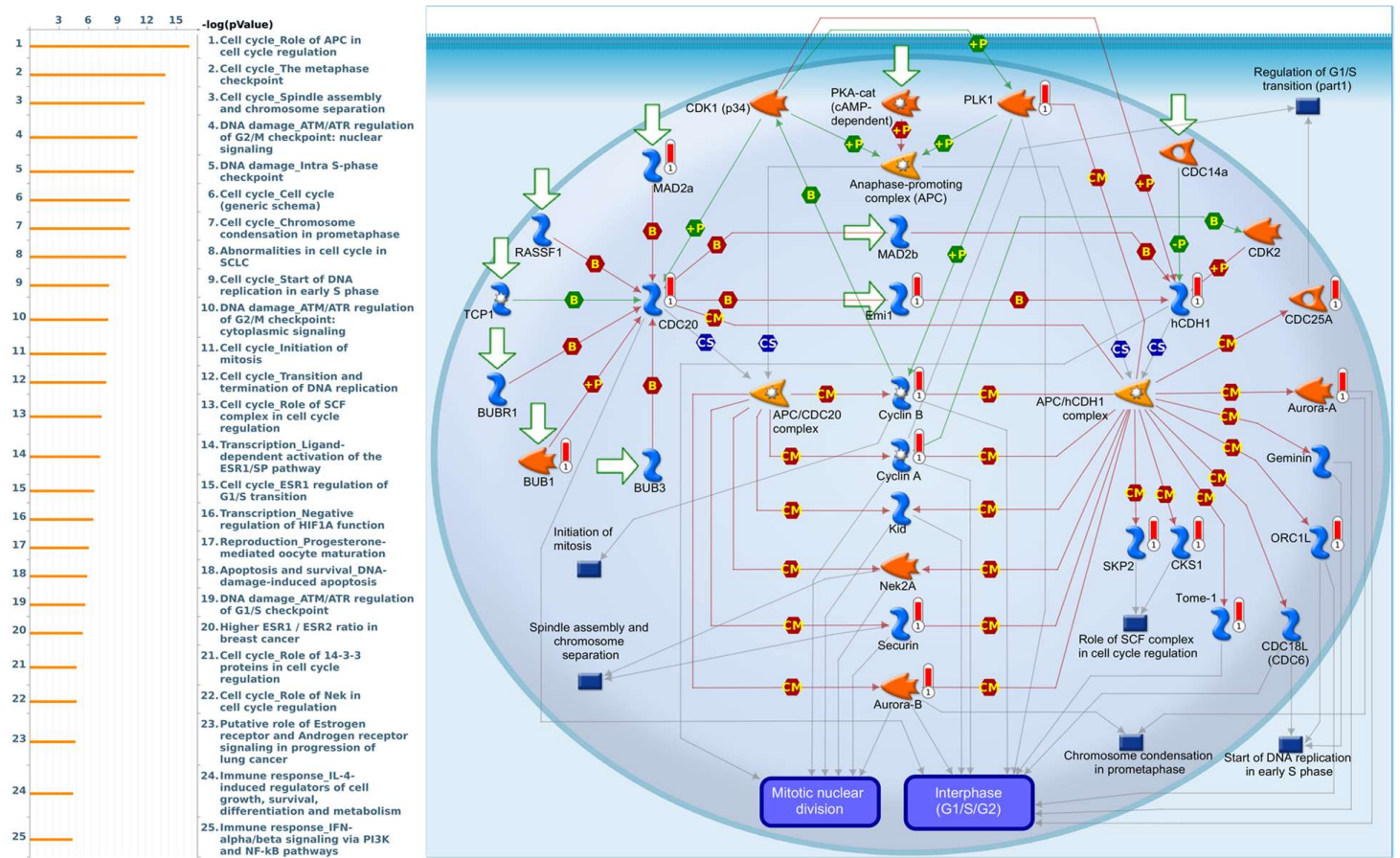

Figure 11. MetaCore pathway analysis of the coexpression gene network of proteasome 20S subunit alpha 7 (PSMA7) in breast cancer patients. We used the MetaCore platform to analyze genes coexpressed with PSMA7 from the associated METABRIC and TCGA datasets, and downstream pathway analyses revealed that “Cell cycle_Role of APC in cell cycle regulation" participates in breast cancer development.
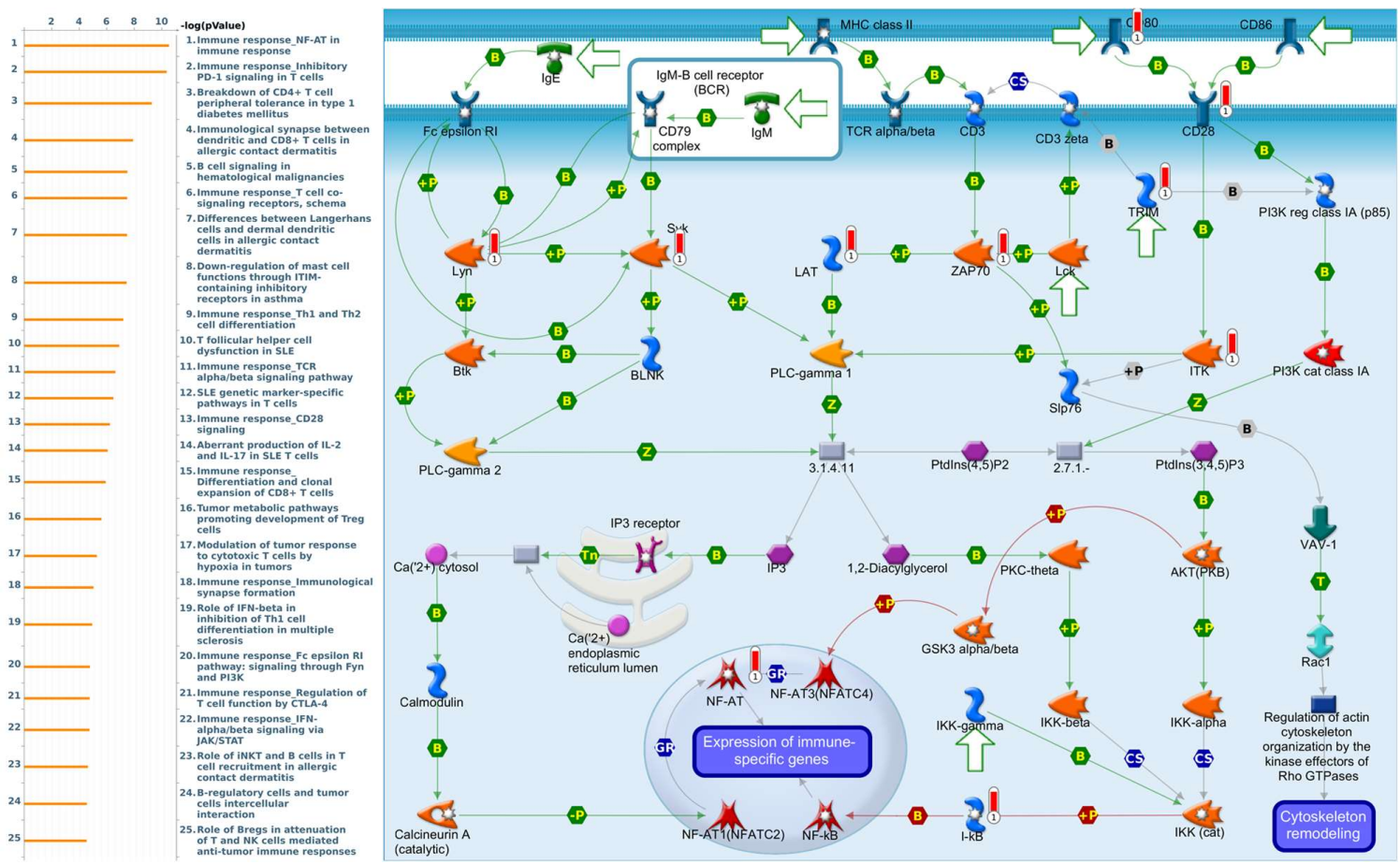

Figure 12. MetaCore pathway analysis of the coexpression gene network of proteasome 20S subunit alpha 8 (PSMA8) in breast cancer patients. We used the MetaCore platform to analyze genes coexpressed with PSMA8 from the associated METABRIC and TCGA datasets, and downstream pathway analyses revealed that "mmune response_NF-AT in immune response" participates in breast cancer development. 


\section{Discussion}

Recently, BRCA overtook lung cancer to rank first among the commonly occurring malignancies in women worldwide [54]. Delays in diagnosis and treatment that worsen the patient's outcomes, along with the enormous burdens resulting from long-term and highcost therapies, have once again undisputedly driven BRCA to become a major public health concern for scientists [55-59]. Clinical practice reveals that the heterogeneity of this disease, observed in both staging systems and histopathologic classification based on molecular standpoints, may complicate the accurate stratification and challenge the selection of respective therapeutic strategies [60-63]. Despite years of extraordinary efforts to enhance our knowledge of its biology and improve surgical treatments and chemotherapies, patient prognoses with advanced BRCA have not substantially improved. Due to deeper insights gained by studies on molecular alterations and advances in molecular characterization and the recognition of novel biomarkers' roles in creating more homogenous subgroups that may guide clinical decisions, determining new biomarkers to improve patient prognoses and develop effective interventions is pivotal [64-67].

We recently reported that the high levels of PSMC family members, including PSMC1, PSMC3, PSMC4, PSMC5, and PSMC6, were positively correlated with the poor survival rates of BRCA patients [45]. Peroxisome proliferator-activated receptor $\gamma(\operatorname{PPAR} \gamma)$ is also associated with ubiquitin-proteasome-dependent degradation and response to the angiotensin II (Ang II) system [68-76]. However, whether PSMA family genes are also involved in BRCA development still needs to be more thoroughly investigated. To the extent of our knowledge, this is the first-ever report on PSMA family genes that provides a comprehensive overview of the genes expressed in relation to patient survival predictions in BRCA. Although the literature has separately confirmed the dysregulation of each gene of the PSMA family that was individually observed in various types of cancer, along with their involvement in other tumor-related issues, only PSMA1 and PSMA2 have so far appeared as potential candidates. PSMA1, alternatively known as proteasome subunit alpha type 1 , encodes the $\alpha 6$ subunit, which makes up the outer ring of the $20 \mathrm{~S}$ core particle. PSMA1 was first reported to be highly overexpressed in BRCA by Deng et al., who, while profiling antibody-inducing immunogens in tumor tissues, identified PSMA1 as a colon cancer marker $[77,78]$. Consistent with previous research, $P S M A 2$, alternatively known as proteasome subunit alpha type 2, encodes the $\alpha 6$ subunit, which makes up the outer ring of the $20 \mathrm{~S}$ core particle. Cancer-related research revealed that, besides the overexpression of PSMA2 mRNA recorded in colorectal cancer stages one to four, as well as in ovarian malignant tumor tissues, targeting PSMA2 by adeno-associated viral vectors was also associated with significant decreases in cell viability and apoptosis induction in basal-like BRCA [79-81]. PSMA3, alternatively known as proteasome subunit alpha type 3, encodes the $\alpha 7$ subunit, which makes up the outer ring of the 205 core particle. Cancer-related reports on the relation of PSMA3 expression and malignancy are limited, including metastatic gastric cancer and cholangiocarcinoma [82,83]. PSMA4, alternatively known as proteasome subunit alpha type 4 , encodes the $\alpha 3$ subunit, which makes up the outer ring of the $20 \mathrm{~S}$ core particle. Although little is known about their roles in cancer, prominent among those were polymorphisms of PSMA4 that play crucial roles in the responsiveness of lung cancer patients to cisplatin-based chemotherapy [84]. PSMA5, alternatively known as proteasome subunit alpha type 5, encodes the outer $\alpha$-rings of the $20 S$ core particle. PSMA5 was significantly upregulated in endometrial cancer, while PSMA6 was significantly upregulated in multiple myeloma patients and pancreatic ductal carcinoma cell models $[85,86]$. PSMA6, alternatively known as proteasome subunit alpha type 6 , encodes the $\alpha 1$ subunit, which makes up the outer ring of the $20 S$ core particle. PSMA7, alternatively known as proteasome subunit alpha type 7, encodes the $\alpha 4$ subunit, which makes up outer ring of the $20 \mathrm{~S}$ core particle. PSMA7, through the mitogen-activated protein kinase (MAPK) pathway, promotes the proliferation and metastasis of gastric cancer [87]. PSMA8, alternatively known as proteasome subunit alpha type 8 , encodes the $\alpha 8$ subunit, which makes up the outer ring of the $20 \mathrm{~S}$ core particle. PSMA 8 is involved in 
many critical processes, such as histone acetylation, DNA repair, and epigenetic regulation. These cellular processes are known for their importance in keeping cells healthy and working properly [88]. This information from the previous literature on the roles of the PSMA gene family is consistent with the present bioinformatic analytical results, in which PSMA genes are highly involved in BRCA and poor prognoses.

\section{Conclusions}

Collectively, he present study could provide useful bioinformatic evidence and potential target genes for prospective studies on the role of PSMA genes in BRCA disease. Most of all, by integrating multiple high-throughput databases, our study revealed that PSMA genes have prognostic and predictive value in BRCA. Therefore, our results can be used as hints for the further examination of this family, and, possibly, they can serve as distinctive biomarkers and potential prognosticators in BRCA. Further research and attention to PSMA family genes will help us better understand BRCA progression and offer new insights into identifying the biomarkers or potential therapeutic targets of BRCA.

Supplementary Materials: The following are available online at https: / www.mdpi.com/article / 10.3390/diagnostics11122220/s1, Supplementary Figure S1. Heatmap of DNA methylation expression levels of the PSMA gene family in breast cancer by MethSurv platform. cg07435350, cg26165081, cg26868250 of PSMA1; cg10778455, cg106226670, cg15202134 of PSMA2; cg08095532, cg14211735 of PSMA4; cg08250978, cg13170147 of PSMA5; cg01757308 of PSMA6; cg17665883 of PSMA7; cg11858305, cg15865827, cg00262344, cg06377543, cg03162994, cg22027766, cg259833544, cg01070760, cg21248196 of PSMA8; displays the highest level of DNA methylation in breast cancer. Table S1: Pathway analysis of proteasome 20S subunit alpha 1 (PSMA1)-coexpressed genes from public breast cancer databases using the MetaCore database (with $p<0.01$ set as the cutoff value) Table S2: Pathway analysis of proteasome 20S subunit alpha 2 (PSMA2)-coexpressed genes from public breast cancer databases using the MetaCore database (with $p<0.01$ set as the cutoff value). Table S3: Pathway analysis of proteasome 20S subunit alpha 3 (PSMA3)-coexpressed genes from public breast cancer databases using the MetaCore database (with $p<0.01$ set as the cutoff value). Table S4: Pathway analysis of proteasome 20S subunit alpha 4 (PSMA4)-coexpressed genes from public breast cancer databases using the MetaCore database (with $p<0.01$ set as the cutoff value). Table S5: Pathway analysis of proteasome 20S subunit alpha 5 (PSMA5)-coexpressed genes from public breast cancer databases using the MetaCore database (with $p<0.01$ set as the cutoff value). Table S6: Pathway analysis of proteasome 20S subunit alpha 6 (PSMA6)-coexpressed genes from public breast cancer databases using the MetaCore database (with $p<0.01$ set as the cutoff value). Table S7: Pathway analysis of proteasome 20S subunit alpha 7 (PSMA7)-coexpressed genes from public breast cancer databases using the MetaCore database (with $p<0.01$ set as the cutoff value). Table S8: Pathway analysis of proteasome 20S subunit alpha 8 (PSMA8)-coexpressed genes from public breast cancer databases using the MetaCore database (with $p<0.01$ set as the cutoff value).

Author Contributions: C.-C.C., Y.-H.L., H.D.K.T., G.A., D.T.M.X., F.F., E.M.P.H., M.A., V.A., P.S.A., Y.-F.W., K.-H.L. and J.-Y.C. performed the bioinformatics analysis, conceived the project, and wrote the manuscript. N.N.P. and N.T.A.T. were responsible for manuscript editing, C.-Y.W. and T.-J.K. performed the data analysis and revised the manuscript. All authors have read and agreed to the published version of the manuscript.

Funding: The study was supported by grants from the Ministry of Science and Technology (MOST) of Taiwan (MOST 110-2320-B-038-017-MY3 to T.J.K., MOST109-2320-B-038-009-MY2 to C.Y.W., and MOST 110-2636-B-038-004 to J.Y.C.) and from the Ministry of Health and Welfare Surcharge of Education Tobacco Products of Taiwan (Wan-Fang Hospital, Chi-Mei Medical Center, and Hualien Tzu-Chi Hospital Joint Cancer Center Grant-Focus on Colon Cancer Research; DP2-109-21121-03-C03-03 and MOHW110-TDU-B-212-144020 awarded to K.H.L.), as well as the "TMU Research Center of Cancer Translational Medicine" from the Featured Areas Research Center Program within the framework of the Higher Education Sprout Project by the Ministry of Education (MOE) in Taiwan.

Institutional Review Board Statement: Not applicable.

Informed Consent Statement: Not applicable. 
Data Availability Statement: The datasets used and/or analyzed during the current study are available from the corresponding author on reasonable request.

Acknowledgments: The authors truly appreciate Daniel P. Chamberlin from the Office of Research and Development at Taipei Medical University for professional English editing. The authors acknowledge the statistical/computational/technical support of the Clinical Data Center, Office of Data Science, Taipei Medical University, Taiwan.

Conflicts of Interest: The authors declare no conflict of interest.

\section{References}

1. Sung, H.; Ferlay, J.; Siegel, R.L.; Laversanne, M.; Soerjomataram, I.; Jemal, A.; Bray, F. Global cancer statistics 2020: GLOBOCAN estimates of incidence and mortality worldwide for 36 cancers in 185 countries. CA Cancer J. Clin. 2021, 71, 209-249. [CrossRef]

2. The American Cancer Society. The Burden of Cancer. Available online: https://canceratlas.cancer.org/the-burden/the-burdenof-cancer/ (accessed on 1 February 2021).

3. World Health Organization. Cancer. 2021. Available online: https://www.who.int/health-topics/cancer\#tab=tab_1 (accessed on 1 February 2021).

4. $\quad$ van 't Veer, L.J.; Dai, H.; van de Vijver, M.J.; He, Y.D.; Hart, A.A.M.; Mao, M.; Peterse, H.L.; van der Kooy, K.; Marton, M.J.; Witteveen, A.T.; et al. Gene expression profiling predicts clinical outcome of breast cancer. Nature 2002, 415, 530-536. [CrossRef]

5. Chen, B.; Tang, H.; Chen, X.; Zhang, G.; Wang, Y.; Xie, X.; Liao, N. Transcriptomic analyses identify key differentially expressed genes and clinical outcomes between triple-negative and non-triple-negative breast cancer. Cancer Manag. Res. 2018, 11, 179-190. [CrossRef]

6. Tang, H.; Huang, X.; Wang, J.; Yang, L.; Kong, Y.; Gao, G.; Zhang, L.; Chen, Z.-S.; Xie, X. circKIF4A acts as a prognostic factor and mediator to regulate the progression of triple-negative breast cancer. Mol. Cancer 2019, 18, 23. [CrossRef] [PubMed]

7. Lawal, B.; Liu, Y.L.; Mokgautsi, N.; Khedkar, H.; Sumitra, M.R.; Wu, A.T.H.; Huang, H.S. Pharmacoinformatics and Preclinical Studies of NSC765690 and NSC765599, Potential STAT3/CDK2/4/6 Inhibitors with Antitumor Activities against NCI60 Human Tumor Cell Lines. Biomedicines 2021, 9, 92. [CrossRef] [PubMed]

8. Lawal, B.; Lee, C.Y.; Mokgautsi, N.; Sumitra, M.R.; Khedkar, H.; Wu, A.T.H.; Huang, H.S. mTOR/EGFR/iNOS/MAP2K1/FGFR/TGFB1 Are Druggable Candidates for N-(2,4-Difluorophenyl)-2',4'-Difluoro-4-Hydroxybiphenyl-3-Carboxamide (NSC765598), With Consequent Anticancer Implications. Front. Oncol. 2021, 11, 656738. [CrossRef]

9. Lawal, B.; Kuo, Y.C.; Sumitra, M.R.; Wu, A.T.H.; Huang, H.S. In vivo Pharmacokinetic and Anticancer Studies of HH-N25, a Selective Inhibitor of Topoisomerase I, and Hormonal Signaling for Treating Breast Cancer. J. Inflamm. Res. 2021, 14, $4901-4913$. [CrossRef] [PubMed]

10. Lawal, B.; Kuo, Y.C.; Wu, A.T.H.; Huang, H.S. BC-N102 suppress breast cancer tumorigenesis by interfering with cell cycle regulatory proteins and hormonal signaling, and induction of time-course arrest of cell cycle at G1/G0 phase. Int. J. Biol. Sci. 2021, 17, 3224-3238. [CrossRef] [PubMed]

11. Chen, B.; Wei, W.; Huang, X.; Xie, X.; Kong, Y.; Dai, D.; Yang, L.; Wang, J.; Tang, H.; Xie, X. circEPSTI1 as a Prognostic Marker and Mediator of Triple-Negative Breast Cancer Progression. Theranostics 2018, 8, 4003-4015. [CrossRef]

12. Thorat, M.A.; Balasubramanian, R. Breast cancer prevention in high-risk women. Best Pract. Res. Clin. Obstet. Gynaecol. 2020, 65, 18-31. [CrossRef]

13. Lin, C.Y.; Lee, C.H.; Chuang, Y.H.; Lee, J.Y.; Chiu, Y.Y.; Wu Lee, Y.H.; Jong, Y.J.; Hwang, J.K.; Huang, S.H.; Chen, L.C.; et al. Membrane protein-regulated networks across human cancers. Nat. Commun. 2019, 10, 3131. [CrossRef]

14. Tsai, H.T.; Huang, C.S.; Tu, C.C.; Liu, C.Y.; Huang, C.J.; Ho, Y.S.; Tu, S.H.; Tseng, L.M.; Huang, C.C. Multi-gene signature of microcalcification and risk prediction among Taiwanese breast cancer. Sci. Rep. 2020, 10, 18276. [CrossRef]

15. Nguyen, H.D.; Liao, Y.C.; Ho, Y.S.; Chen, L.C.; Chang, H.W.; Cheng, T.C.; Liu, D.; Lee, W.R.; Shen, S.C.; Wu, C.H.; et al. The $\alpha 9$ Nicotinic Acetylcholine Receptor Mediates Nicotine-Induced PD-L1 Expression and Regulates Melanoma Cell Proliferation and Migration. Cancers 2019, 11, 1991. [CrossRef]

16. Lee, K.L.; Kuo, Y.C.; Ho, Y.S.; Huang, Y.H. Triple-Negative Breast Cancer: Current Understanding and Future Therapeutic Breakthrough Targeting Cancer Stemness. Cancers 2019, 11, 1334. [CrossRef]

17. Sever, R.; Brugge, J.S. Signal transduction in cancer. Cold Spring Harb. Perspect. Med. 2015, 5, a006098. [CrossRef] [PubMed]

18. Herceg, Z.; Hainaut, P. Genetic and epigenetic alterations as biomarkers for cancer detection, diagnosis and prognosis. Mol. Oncol. 2007, 1, 26-41. [CrossRef]

19. Chakravarthi, B.V.S.K.; Nepal, S.; Varambally, S. Genomic and Epigenomic Alterations in Cancer. Am. J. Pathol. 2016, 186, 1724-1735. [CrossRef] [PubMed]

20. Collins, G.A.; Goldberg, A.L. The logic of the 26S proteasome. Cell 2017, 169, 792-806. [CrossRef] [PubMed]

21. Haselbach, D.; Schrader, J.; Lambrecht, F.; Henneberg, F.; Chari, A.; Stark, H. Long-range allosteric regulation of the human 26S proteasome by $20 \mathrm{~S}$ proteasome-targeting cancer drugs. Nat. Commun. 2017, 8, 1-8. [CrossRef]

22. Hwang, H.J.; Park, Y.; Kim, Y.K. UPF1: From mRNA Surveillance to Protein Quality Control. Biomedicines 2021, 9, 995. [CrossRef] 
23. Li, J.; Pohl, L.; Schüler, J.; Korzeniewski, N.; Reimold, P.; Kaczorowski, A.; Hou, W.; Zschäbitz, S.; Nientiedt, C.; Jäger, D.; et al. Targeting the Proteasome in Advanced Renal Cell Carcinoma: Complexity and Limitations of Patient-Individualized Preclinical Drug Discovery. Biomedicines 2021, 9, 627. [CrossRef] [PubMed]

24. Wolf, P. Targeted Toxins for the Treatment of Prostate Cancer. Biomedicines 2021, 9, 986. [CrossRef] [PubMed]

25. Chang, S.C.; Hung, C.S.; Zhang, B.X.; Hsieh, T.H.; Hsu, W.; Ding, J.L. A Novel Signature of CCNF-Associated E3 Ligases Collaborate and Counter Each Other in Breast Cancer. Cancers 2021, 13, 2873. [CrossRef]

26. Chang, S.C.; Hsu, W.; Su, E.C.; Hung, C.S.; Ding, J.L. Human FBXL8 Is a Novel E3 Ligase Which Promotes BRCA Metastasis by Stimulating Pro-Tumorigenic Cytokines and Inhibiting Tumor Suppressors. Cancers 2020, 12, 2210. [CrossRef]

27. Chang, S.C.; Ding, J.L. Ubiquitination and SUMOylation in the chronic inflammatory tumor microenvironment. Biochim. Biophys. Acta Rev. Cancer 2018, 1870, 165-175. [CrossRef]

28. Ebstein, F.; Poli Harlowe, M.C.; Studencka-Turski, M.; Krüger, E. Contribution of the Unfolded Protein Response (UPR) to the Pathogenesis of Proteasome-Associated Autoinflammatory Syndromes (PRAAS). Front. Immunol. 2019, 10, 2756. [CrossRef] [PubMed]

29. Li, Y.; Huang, J.; Sun, J.; Xiang, S.; Yang, D.; Ying, X.; Lu, M.; Li, H.; Ren, G. The transcription levels and prognostic values of seven proteasome alpha subunits in human cancers. Oncotarget 2017, 8, 4501. [CrossRef]

30. Mairinger, F.D.; Walter, R.F.H.; Theegarten, D.; Hager, T.; Vollbrecht, C.; Christoph, D.C.; Worm, K.; Ting, S.; Werner, R.; Stamatis, G.; et al. Gene Expression Analysis of the 26S Proteasome Subunit PSMB4 Reveals Significant Upregulation, Different Expression and Association with Proliferation in Human Pulmonary Neuroendocrine Tumours. J. Cancer 2014, 5, 646-654. [CrossRef]

31. Wei, W.; Zou, Y.; Jiang, Q.; Zhou, Z.; Ding, H.; Yan, L.; Yang, S. PSMB5 is associated with proliferation and drug resistance in triple-negative breast cancer. Int. J. Biol. Markers 2017, 33, 102-108. [CrossRef] [PubMed]

32. Wang, C.-Y.; Li, C.-Y.; Hsu, H.-P.; Cho, C.-Y.; Yen, M.-C.; Weng, T.-Y.; Chen, W.-C.; Hung, Y.-H.; Lee, K.-T.; Hung, J.-H.; et al. PSMB5 plays a dual role in cancer development and immunosuppression. Am. J. Cancer Res. 2017, 7, $2103-2120$.

33. Liu, Y.; Chen, L.; Yuan, H.; Guo, S.; Wu, G. LncRNA DANCR Promotes Sorafenib Resistance via Activation of IL-6/STAT3 Signaling in Hepatocellular Carcinoma Cells. Onco Targets Ther. 2020, 13, 1145-1157. [CrossRef]

34. Barrett, T.; Wilhite, S.E.; Ledoux, P.; Evangelista, C.; Kim, I.F.; Tomashevsky, M.; Marshall, K.A.; Phillippy, K.H.; Sherman, P.M.; Holko, M.; et al. NCBI GEO: Archive for functional genomics data sets-update. Nucleic Acids Res. 2013, 41, D991-D995. [CrossRef]

35. Lin, J.C.; Liu, T.P.; Yang, P.M. CDKN2A-Inactivated Pancreatic Ductal Adenocarcinoma Exhibits Therapeutic Sensitivity to Paclitaxel: A Bioinformatics Study. J. Clin. Med. 2020, 9, 4019. [CrossRef]

36. Lin, T.Y.; Wang, P.W.; Huang, C.H.; Yang, P.M.; Pan, T.L. Characterizing the Relapse Potential in Different Luminal Subtypes of Breast Cancers with Functional Proteomics. Int. J. Mol. Sci. 2020, 21, 77. [CrossRef]

37. Liu, L.W.; Hsieh, Y.Y.; Yang, P.M. Bioinformatics Data Mining Repurposes the JAK2 (Janus Kinase 2) Inhibitor Fedratinib for Treating Pancreatic Ductal Adenocarcinoma by Reversing the KRAS (Kirsten Rat Sarcoma 2 Viral Oncogene Homolog)-Driven Gene Signature. J. Pers. Med. 2020, 10, 130. [CrossRef]

38. Yang, P.M.; Hsieh, Y.Y.; Du, J.L.; Yen, S.C.; Hung, C.F. Sequential Interferon $\beta$-Cisplatin Treatment Enhances the Surface Exposure of Calreticulin in Cancer Cells via an Interferon Regulatory Factor 1-Dependent Manner. Biomolecules 2020, 10, 643. [CrossRef] [PubMed]

39. Yang, P.M.; Lin, L.S.; Liu, T.P. Sorafenib Inhibits Ribonucleotide Reductase Regulatory Subunit M2 (RRM2) in Hepatocellular Carcinoma Cells. Biomolecules 2020, 10, 117. [CrossRef] [PubMed]

40. Rhodes, D.R.; Kalyana-Sundaram, S.; Mahavisno, V.; Varambally, R.; Yu, J.; Briggs, B.B.; Barrette, T.R.; Anstet, M.J.; Kincead-Beal, C.; Kulkarni, P.; et al. Oncomine 3.0: Genes, pathways, and networks in a collection of 18,000 cancer gene expression profiles. Neoplasia 2007, 9, 166-180. [CrossRef]

41. Huang, T.-C.; Lee, P.-T.; Wu, M.-H.; Huang, C.-C.; Ko, C.-Y.; Lee, Y.-C.; Lin, D.-Y.; Cheng, Y.-W.; Lee, K.-H. Distinct roles and differential expression levels of Wnt5a mRNA isoforms in colorectal cancer cells. PLoS ONE 2017, 12, e0181034. [CrossRef] [PubMed]

42. Cheng, L.-C.; Chao, Y.-J.; Overman, M.J.; Wang, C.-Y.; Phan, N.N.; Chen, Y.-L.; Wang, T.-W.; Hsu, H.-P.; Shan, Y.-S.; Lai, M.-D Increased expression of secreted frizzled related protein 1 (SFRP1) predicts ampullary adenocarcinoma recurrence. Sci. Rep. 2020, 10, 1-16. [CrossRef]

43. Huang, T.H.; Mokgautsi, N.; Huang, Y.J.; Wu, A.T.H.; Huang, H.S. Comprehensive Omics Analysis of a Novel Small-Molecule Inhibitor of Chemoresistant Oncogenic Signatures in Colorectal Cancer Cell with Antitumor Effects. Cells 2021, $10,1970$. [CrossRef]

44. Yadav, V.K.; Huang, Y.J.; George, T.A.; Wei, P.L.; Sumitra, M.R.; Ho, C.L.; Chang, T.H.; Wu, A.T.H.; Huang, H.S. Preclinical Evaluation of the Novel Small-Molecule MSI-N1014 for Treating Drug-Resistant Colon Cancer via the LGR5/ $\beta$-catenin/miR-142$3 p$ Network and Reducing Cancer-Associated Fibroblast Transformation. Cancers 2020, 12, 1590. [CrossRef]

45. Lawal, B.; Wang, Y.C.; Wu, A.T.H.; Huang, H.S. Pro-Oncogenic c-Met/EGFR, Biomarker Signatures of the Tumor Microenvironment are Clinical and Therapy Response Prognosticators in Colorectal Cancer, and Therapeutic Targets of 3-Phenyl-2Hbenzo[e][1,3]-Oxazine-2,4(3H)-Dione Derivatives. Front. Pharmacol. 2021, 12, 691234. [CrossRef] [PubMed]

46. Chandrashekar, D.S.; Bashel, B.; Balasubramanya, S.A.H.; Creighton, C.J.; Ponce-Rodriguez, I.; Chakravarthi, B.; Varambally, S. UALCAN: A Portal for Facilitating Tumor Subgroup Gene Expression and Survival Analyses. Neoplasia 2017, 19, 649-658. [CrossRef] [PubMed] 
47. Györffy, B.; Lanczky, A.; Eklund, A.C.; Denkert, C.; Budczies, J.; Li, Q.; Szallasi, Z. An online survival analysis tool to rapidly assess the effect of 22,277 genes on breast cancer prognosis using microarray data of 1,809 patients. Breast Cancer Res. Treat. 2010, 123, 725-731. [CrossRef]

48. $\quad$ Anuraga, G.; Wang, W.-J.; Phan, N.N.; An Ton, N.T.; Ta, H.D.K.; Berenice Prayugo, F.; Minh Xuan, D.T.; Ku, S.-C.; Wu, Y.-F.; Andriani, V.; et al. Potential Prognostic Biomarkers of NIMA (Never in Mitosis, Gene A)-Related Kinase (NEK) Family Members in Breast Cancer. J. Pers. Med. 2021, 11, 1089. [CrossRef]

49. Lin, Y.Y.; Wang, C.Y.; Phan, N.N.; Chiao, C.C.; Li, C.Y.; Sun, Z.; Hung, J.H.; Chen, Y.L.; Yen, M.C.; Weng, T.Y.; et al. PODXL2 maintains cellular stemness and promotes breast cancer development through the Rac1/Akt pathway. Int. J. Med. Sci. 2020, 17, 1639-1651. [CrossRef]

50. Wang, C.Y.; Chang, Y.C.; Kuo, Y.L.; Lee, K.T.; Chen, P.S.; Cheung, C.H.A.; Chang, C.P.; Phan, N.N.; Shen, M.R.; Hsu, H.P. Mutation of the PTCH1 gene predicts recurrence of breast cancer. Sci. Rep. 2019, 9, 16359. [CrossRef] [PubMed]

51. Cho, C.Y.; Lee, K.T.; Chen, W.C.; Wang, C.Y.; Chang, Y.S.; Huang, H.L.; Hsu, H.P.; Yen, M.C.; Lai, M.Z.; Lai, M.D. MST3 promotes proliferation and tumorigenicity through the VAV2/Rac1 signal axis in breast cancer. Oncotarget 2016, 7, 14586-14604. [CrossRef]

52. Uhlén, M.; Fagerberg, L.; Hallström, B.M.; Lindskog, C.; Oksvold, P.; Mardinoglu, A.; Sivertsson, Å.; Kampf, C.; Sjöstedt, E.; Asplund, A.; et al. Proteomics. Tissue-based map of the human proteome. Science 2015, 347, 1260419. [CrossRef]

53. Ta, H.D.K.; Wang, W.-J.; Phan, N.N.; An Ton, N.T.; Anuraga, G.; Ku, S.-C.; Wu, Y.-F.; Wang, C.-Y.; Lee, K.-H. Potential Therapeutic and Prognostic Values of LSM Family Genes in Breast Cancer. Cancers 2021, 13, 4902. [CrossRef] [PubMed]

54. Choy, T.K.; Wang, C.Y.; Phan, N.N.; Khoa Ta, H.D.; Anuraga, G.; Liu, Y.H.; Wu, Y.F.; Lee, K.H.; Chuang, J.Y.; Kao, T.J. Identification of Dipeptidyl Peptidase (DPP) Family Genes in Clinical Breast Cancer Patients via an Integrated Bioinformatics Approach. Diagnostics 2021, 11, 1204. [CrossRef]

55. Chen, P.Y.; Chao, T.Y.; Hsu, H.J.; Wang, C.Y.; Lin, C.Y.; Gao, W.Y.; Wu, M.J.; Yen, J.H. The Lipid-Modulating Effect of Tangeretin on the Inhibition of Angiopoietin-like 3 (ANGPTL3) Gene Expression through Regulation of LXR $\alpha$ Activation in Hepatic Cells. Int. J. Mol. Sci. 2021, 22, 9853. [CrossRef] [PubMed]

56. Kao, T.J.; Wu, C.C.; Phan, N.N.; Liu, Y.H.; Ta, H.D.K.; Anuraga, G.; Wu, Y.F.; Lee, K.H.; Chuang, J.Y.; Wang, C.Y. Prognoses and genomic analyses of proteasome 26S subunit, ATPase (PSMC) family genes in clinical breast cancer. Aging 2021, 13, 17970. [CrossRef]

57. Khoa Ta, H.D.; Tang, W.C.; Phan, N.N.; Anuraga, G.; Hou, S.Y.; Chiao, C.C.; Liu, Y.H.; Wu, Y.F.; Lee, K.H.; Wang, C.Y. Analysis of LAGEs Family Gene Signature and Prognostic Relevance in Breast Cancer. Diagnostics 2021, 11, 726. [CrossRef] [PubMed]

58. Hagerling, C.; Gonzalez, H.; Salari, K.; Wang, C.-Y.; Lin, C.; Robles, I.; van Gogh, M.; Dejmek, A.; Jirström, K.; Werb, Z. Immune effector monocyte-neutrophil cooperation induced by the primary tumor prevents metastatic progression of breast cancer. Proc. Natl. Acad. Sci. USA 2019, 116, 21704-21714. [CrossRef] [PubMed]

59. Huang, B.F.; Tzeng, H.E.; Chen, P.C.; Wang, C.Q.; Su, C.M.; Wang, Y.; Hu, G.N.; Zhao, Y.M.; Wang, Q.; Tang, C.H. HMGB1 genetic polymorphisms are biomarkers for the development and progression of breast cancer. Int. J. Med. Sci. 2018, 15, 580-586. [CrossRef] [PubMed]

60. Chen, P.S.; Hsu, H.P.; Phan, N.N.; Yen, M.C.; Chen, F.W.; Liu, Y.W.; Lin, F.P.; Feng, S.Y.; Cheng, T.L.; Yeh, P.H.; et al. CCDC167 as a potential therapeutic target and regulator of cell cycle-related networks in breast cancer. Aging 2021, 13, 4157-4181. [CrossRef]

61. Wang, C.Y.; Chao, Y.J.; Chen, Y.L.; Wang, T.W.; Phan, N.N.; Hsu, H.P.; Shan, Y.S.; Lai, M.D. Upregulation of peroxisome proliferator-activated receptor- $\alpha$ and the lipid metabolism pathway promotes carcinogenesis of ampullary cancer. Int. J. Med. Sci. 2021, 18, 256-269. [CrossRef] [PubMed]

62. Chen, Y.L.; Wang, C.Y.; Fang, J.H.; Hsu, H.P. Serine/threonine-protein kinase 24 is an inhibitor of gastric cancer metastasis through suppressing CDH1 gene and enhancing stemness. Am. J. Cancer Res. 2021, 11, 4277-4293. [PubMed]

63. Wu, C.C.; Ekanem, T.I.; Phan, N.N.; Loan, D.T.T.; Hou, S.Y.; Lee, K.H.; Wang, C.Y. Gene signatures and prognostic analyses of the Tob/BTG pituitary tumor-transforming gene (PTTG) family in clinical breast cancer patients. Int. J. Med. Sci. 2020, 17, 3112-3124. [CrossRef] [PubMed]

64. Bray, F.; Ferlay, J.; Soerjomataram, I.; Siegel, R.L.; Torre, L.A.; Jemal, A. Global cancer statistics 2018: GLOBOCAN estimates of incidence and mortality worldwide for 36 cancers in 185 countries. CA Cancer J. Clin. 2018, 68, 394-424. [CrossRef] [PubMed]

65. Rivera-Franco, M.M.; Leon-Rodriguez, E. Delays in Breast Cancer Detection and Treatment in Developing Countries. Breast Cancer 2018, 12, 1178223417752677. [CrossRef] [PubMed]

66. Ji, P.; Gong, Y.; Jin, M.-L.; Hu, X.; Di, G.-H.; Shao, Z.-M. The Burden and Trends of Breast Cancer From 1990 to 2017 at the Global, Regional, and National Levels: Results from the Global Burden of Disease Study 2017. Front. Oncol. 2020, 10, 650. [CrossRef] [PubMed]

67. Turashvili, G.; Brogi, E. Tumor Heterogeneity in Breast Cancer. Front. Med. 2017, 4, 227. [CrossRef]

68. Sun, L.; Bian, K. The Nuclear Export and Ubiquitin-Proteasome-Dependent Degradation of PPAR $\gamma$ Induced by Angiotensin II. Int. J. Biol. Sci. 2019, 15, 1215-1224. [CrossRef] [PubMed]

69. Fang, S.; Sigmund, C.D. PPAR $\gamma$ and RhoBTB1 in hypertension. Curr. Opin. Nephrol. Hypertens. 2020, 29, 161-170. [CrossRef]

70. Lee, K.W.; Kwak, S.H.; Koo, Y.D.; Cho, Y.K.; Lee, H.M.; Jung, H.S.; Cho, Y.M.; Park, Y.J.; Chung, S.S.; Park, K.S. F-box only protein 9 is an E3 ubiquitin ligase of PPAR $\gamma$. Exp. Mol. Med. 2016, 48, e234. [CrossRef]

71. Li, J.J.; Wang, R.; Lama, R.; Wang, X.; Floyd, Z.E.; Park, E.A.; Liao, F.F. Ubiquitin Ligase NEDD4 Regulates PPAR $\gamma$ Stability and Adipocyte Differentiation in 3T3-L1 Cells. Sci. Rep. 2016, 6, 38550. [CrossRef] 
72. Farhoud, M.H.; Nijtmans, L.G.; Wanders, R.J.; Wessels, H.J.; Lasonder, E.; Janssen, A.J.; Rodenburg, R.R.; van den Heuvel, L.P.; Smeitink, J.A. Impaired ubiquitin-proteasome-mediated PGC-1 $\alpha$ protein turnover and induced mitochondrial biogenesis secondary to complex-I deficiency. Proteomics 2012, 12, 1349-1362. [CrossRef] [PubMed]

73. Stravodimou, A.; Mazzoccoli, G.; Voutsadakis, I.A. Peroxisome proliferator-activated receptor gamma and regulations by the ubiquitin-proteasome system in pancreatic cancer. PPAR Res. 2012, 2012, 367450. [CrossRef]

74. Wang, Z.; Dou, X.; Gu, D.; Shen, C.; Yao, T.; Nguyen, V.; Braunschweig, C.; Song, Z. 4-Hydroxynonenal differentially regulates adiponectin gene expression and secretion via activating PPAR $\gamma$ and accelerating ubiquitin-proteasome degradation. Mol. Cell Endocrinol. 2012, 349, 222-231. [CrossRef] [PubMed]

75. Kilroy, G.; Kirk-Ballard, H.; Carter, L.E.; Floyd, Z.E. The ubiquitin ligase Siah2 regulates PPAR $\gamma$ activity in adipocytes. Endocrinology 2012, 153, 1206-1218. [CrossRef] [PubMed]

76. Voutsadakis, I.A. Peroxisome proliferator activated receptor- $\gamma$ and the ubiquitin-proteasome system in colorectal cancer. World J. Gastrointest. Oncol. 2010, 2, 235-241. [CrossRef]

77. Deng, S.-S.; Xing, T.-Y.; Zhou, H.-Y.; Xiong, R.-H.; Lu, Y.-G.; Wen, B.; Liu, S.-Q.; Yang, H.-J. Comparative proteome analysis of breast cancer and adjacent normal breast tissues in human. Genom. Proteom. Bioinform. 2006, 4, 165-172. [CrossRef]

78. Yang, Q.; Roehrl, M.H.; Wang, J.Y. Proteomic profiling of antibody-inducing immunogens in tumor tissue identifies PSMA1, LAP3, ANXA3, and maspin as colon cancer markers. Oncotarget 2017, 9, 3996-4019. [CrossRef] [PubMed]

79. Yue, W.; Sun, L.-Y.; Li, C.-H.; Zhang, L.-X.; Xue, T. Screening and identification of ovarian carcinomas related genes. Ai Zheng Chin. J. Cancer 2004, 23, 141-145.

80. Qi, J.; Hu, Z.; Liu, S.; Li, F.; Wang, S.; Wang, W.; Sheng, X.; Feng, L. Comprehensively Analyzed Macrophage-Regulated Genes Indicate That PSMA2 Promotes Colorectal Cancer Progression. Front. Oncol. 2020, 10, 618902. [CrossRef] [PubMed]

81. Pinto, C.; Silva, G.; Ribeiro, A.S.; Oliveira, M.; Garrido, M.; Bandeira, V.S.; Nascimento, A.; Coroadinha, A.S.; Peixoto, C.; Barbas, A.; et al. Evaluation of AAV-mediated delivery of shRNA to target basal-like breast cancer genetic vulnerabilities. J. Biotechnol. 2019, 300, 70-77. [CrossRef]

82. Verathamjamras, C.; Weeraphan, C.; Chokchaichamnankit, D.; Watcharatanyatip, K.; Subhasitanont, P.; Diskul-Na-Ayudthaya, P.; Mingkwan, K.; Luevisadpaibul, V.; Chutipongtanate, S.; Champattanachai, V.; et al. Secretomic profiling of cells from hollow fiber bioreactor reveals PSMA3 as a potential cholangiocarcinoma biomarker. Int. J. Oncol. 2017, 51, 269-280. [CrossRef]

83. Ding, X.Q.; Wang, Z.Y.; Xia, D.; Wang, R.X.; Pan, X.R.; Tong, J.H. Proteomic Profiling of Serum Exosomes from Patients with Metastatic Gastric Cancer. Front. Oncol. 2020, 10, 1113. [CrossRef]

84. Wang, T.; Chen, T.; Thakur, A.; Liang, Y.; Gao, L.; Zhang, S.; Tian, Y.; Jin, T.; Liu, J.J.; Chen, M. Association of PSMA4 polymorphisms with lung cancer susceptibility and response to cisplatin-based chemotherapy in a Chinese Han population. Clin. Transl. Oncol. 2015, 17, 564-569. [CrossRef] [PubMed]

85. Wang, L.; Zhou, W.; Li, H.; Yang, H.; Shan, N. Clinical Significance, Cellular Function, and Potential Molecular Pathways of CCT7 in Endometrial Cancer. Front. Oncol. 2020, 10, 1468. [CrossRef] [PubMed]

86. Zmorzyński, S.; Popek-Marciniec, S.; Styk, W.; Wojcierowska-Litwin, M.; Korszeń-Pilecka, I.; Szudy-Szczyrek, A.; Chocholska, S.; Hus, M.; Filip, A.A. The Impact of the NOD2/CARD15 Variant (3020insC) and PSMA6 Polymorphism (-8C $>$ G) on the Development and Outcome of Multiple Myeloma. Biomed. Res. Int. 2020, 2020, 7629456. [CrossRef] [PubMed]

87. Xia, S.; Ji, L.; Tang, L.; Zhang, L.; Zhang, X.; Tang, Q.; Feng, Z.; Lu, L. Proteasome Subunit Alpha Type 7 Promotes Proliferation and Metastasis of Gastric Cancer Through MAPK Signaling Pathway. Dig. Dis. Sci. 2021. [CrossRef]

88. Qian, M.-X.; Pang, Y.; Liu, C.H.; Haratake, K.; Du, B.-Y.; Ji, D.-Y.; Wang, G.-F.; Zhu, Q.-Q.; Song, W.; Yu, Y.; et al. Acetylationmediated proteasomal degradation of core histones during DNA repair and spermatogenesis. Cell 2013, 153, 1012-1024. [CrossRef] 